\title{
Variable fatty acid composition of the pelagic appendicularian Oikopleura dioica in response to dietary quality and quantity
}

\author{
Christofer Troedsson ${ }^{1}$, Otto Grahl-Nielsen ${ }^{2}$, Eric M. Thompson ${ }^{1, *}$ \\ ${ }^{1}$ Sars International Centre for Marine Molecular Biology, Thormøhlensgate 55, 5008 Bergen, Norway \\ ${ }^{2}$ Department of Chemistry, University of Bergen, Allegaten 41, 5007 Bergen, Norway
}

\begin{abstract}
In marine zooplankton communities, appendicularians are second in abundance to copepods, and there is evidence that they are an important dietary component for larvae of several fish species. As various algal species upon which the appendicularian Oikopleura dioica grazes differ significantly in their fatty acid compositions, we have examined how this filter feeder translates diets that differ in quality or quantity into its own fatty acid composition. By feeding O. dioica diets containing either a single diatom or single flagellate species, we demonstrated that the fatty acid composition of $O$. dioica reflects dietary quality. Quantitative differences in the amount of fatty acids in the diet also directly led to quantitative differences in fatty acid content of the animal, consistent with differences in reproductive output reported earlier. Under the same dietary regimes, males differed from females in fatty acid composition. Among these differences, females had higher amounts of eicosapentaenoic acid (EPA) and docosahexaenoic acid (DHA), important for larval development. Analysis of fatty acid composition of fecal pellets revealed selective assimilation of some fatty acids by the animals, including EPA and DHA. Overall, consistent with data on other zooplanktonic filter feeders, the fatty acid composition of $O$. dioica reflected dietary composition, indicating that the nutritional quality of primary production would be transferred to predators of this component of zooplankton without substantial intermediary modifications.
\end{abstract}

KEY WORDS: Life history $\cdot$ Zooplankton $\cdot$ Filter feeding $\cdot$ Larval development $\cdot$ Flagellate $\cdot$ Diatom

\section{INTRODUCTION}

Appendicularians generate a complex, extracellular, gelatinous, filter feeding house composed of mucopolysaccharides (Spada et al. 2001, Thompson et al. 2001). This filter feeding structure enables appendicularians to feed on algae, as well as particulate organic carbon (POC) down to $0.2 \mu \mathrm{m}$ (Flood et al. 1992, Fernández et al. 2004). This makes them an important component in marine ecosystems, where they provide a shortcut in the food web by directly transferring energy from very small particles (e.g. submicron colloids, prochlorophytes, cyanobacteria, bacterioplankton, nanoflagellates) to much larger predators such as larval and adult fish (Deibel 1998).
Among appendicularians, Oikopleura dioica is found in all major oceans (Fenaux et al. 1998). The generation time, which is extremely short for a complex metazoan $\left(7 \mathrm{~d}\right.$ at $\left.15^{\circ} \mathrm{C}\right)$, combined with high fecundity, yields a relationship between animal size and maximal intrinsic rate of natural increase $\left(r_{\max }\right)$ that considerably exceeds values recorded for other poikilothermic metazoans (Troedsson et al. 2002). Appendicularians are, thus, able to exploit favorable environments quickly, resulting in patchy distributions and densities attaining 53000 ind. $\mathrm{m}^{-3}$ (Uye \& Ichino 1995). An increased understanding of the general life history parameters of $O$. dioica has been gained in recent years, where filter feeding, development and growth rates have been the main focus. However, data on the 
composition and nutritional value of appendicularians are very limited. Deibel et al. (1992) studied the major lipid classes of $O$. vanhoffeni at different ontogenetic stages under both pre- and post-bloom conditions, and demonstrated a change in the total fatty acid composition before and after the spring bloom. They suggested that there is little evidence of energy storage in O. vanhoffeni, with the predominant strategy seeming to be an allocation towards rapid somatic and reproductive growth. $O$. dioica has a very short generation time, with unusually high population increases (Troedsson et al. 2002). Energy will be allocated into reproductive tissues in an opportunistic way and storage for longterm survival is limited. However, a strategy of fixed somatic growth with no apparent storage could lead to high death rates, even over short durations of food depletion. Storage, particularly in the form of fat droplets, would therefore enhance survival as well as reducing the risk of food depletion as reproductive allocation begins.

In view of their appropriate size range for ingestion by fish larvae, and capacity for rapid blooms, appendicularians are also likely to be an important factor for successful recruitment in some fish populations, and this has been documented in several fish species (Shelbourne 1962, Gadomski \& Boelert 1984, Mousseau et al. 1998, Ticina et al. 2000, Watanabe et al. 2002, Hasegawa et al. 2003). Studies of marine fishes have shown that fish larvae are sensitive to low levels of some n-3 polyunsaturated fatty acids (PUFAs), particularly eicosapentaenoic acid (EPA $; 20: 5 n 3)$ and docosahexaenoic acid (DHA; 22:6n3) (Støttrup \& Attramadal 1992, Koven et al. 1993, Kraul et al. 1993, Lochmann \& Gatlin 1993, Watanabe 1993, Whyte et al. 1994). In some fish, the level of DHA has a significant effect on survival as well as on growth rates (Watanabe 1993). Marine animals have limited abilities to synthesize long-chain PUFA from short-chain PUFA (Dunstan et al. 1996). This means that they must obtain these fatty acids from the diet (essential fatty acids). As appendicularians are thought to be an important food source for a number of fish species, a significant question is how the fatty acid composition of appendicularians changes with different composition and quantity of food. To investigate how Oikopleura dioica assimilates and modifies fatty acids when experiencing diets differing qualitatively in fatty acid content, animals were fed either a strict diet of Isochrysis sp., which is high in DHA and low in EPA content, or Chaetoceros calcitrans, which, in contrast, is high in EPA and low in DHA (Napolitano et al. 1990). Subsequently, we examined the storage and assimilation of fatty acids under abundant and limited food regimes, which were identical in fatty acid composition but differed in total fatty acid content (Troedsson et al. 2002).

\section{MATERIALS AND METHODS}

Culture of algae. Fresh inoculates were made from static cultures of Isochrysis sp. (Prymnesiophyta, CCAP 927/14; diameter $=4.5 \mu \mathrm{m}$, carbon $=10.6 \pm$ $0.3 \mathrm{pg} \mathrm{cell}{ }^{-1}$, fatty acid $=1.3 \pm 0.4 \mathrm{pg} \mathrm{cell}^{-1}$ ) and Chaetoceros calcitrans (Bacillariophyta, CCAP 1010/ 11 , diameter $=3 \mu \mathrm{m}$, length $=4.5 \mu \mathrm{m}$, carbon $=4.6 \pm$ $0.3 \mathrm{pg} \mathrm{cell}^{-1}$, fatty acid $=1.0 \pm 0.4 \mathrm{pg} \mathrm{cell}^{-1}$ ). Nutrients and silica (for $C$. calcitrans) were added, and they were grown in 21 plastic bags with constant light and air bubbles for agitation. The same strain was used throughout the experiments. To avoid fluctuations in fatty acid composition of the algae, qualitative fatty acid analysis was carried out at regular intervals after inoculation. Experiments were then conducted using algae in the exponential growth phase $\left(2\right.$ to $6 \times 10^{6}$ cells ml ${ }^{-1}$ for Isochrysis sp.; 4 to $8 \times 10^{6}$ cells ml $^{-1}$ for C. calcitrans) during which they had stable lipid composition. These algae were selected for experimentation because they have been well characterised in the culture of Oikopleura dioica (Gorsky 1980, Troedsson et al. 2002), were similar in total fatty acid content, but differed significantly in fatty acid composition (Tables A \& B of Appendix 1, see www.int-res.com/ journals/suppl/troedsson_appendix.pdf), and they are representative of the progression from diatom to flagellate blooms in natural ecosystems.

Collection and culture of animals. Oikopleura dioica was collected in the coastal area of Bergen, Norway, using a plankton net with a large volume codend, and cultured in wet laboratory facilities. Animals were cultured in 61 plastic beakers (Cambro) using a plastic paddle $(25 \mathrm{~cm}$ deep $\times 7 \mathrm{~cm}$ wide) rotating at $15 \mathrm{rpm}$ to keep the animals and algae suspended in the water column. Seawater from a depth of 4 to $8 \mathrm{~m}$ was filtered through 3 Hytrex II Cartridge Filters $(20,10$ and $1 \mu \mathrm{m}$, respectively). The filtered seawater was then passed through a Merck charcoal filter with a 0.25 to $1 \mathrm{~mm}$ gradient and exposed to an Aqua-Care UVlight $(254 \mathrm{~nm}, 10 \mathrm{~W})$ to sterilize the seawater. Cultures were run at $15^{\circ} \mathrm{C}$, illuminated by $36 \mathrm{~W} / 20$ cool white fluorescent light tubes. To establish a generation of animals, 40 to 45 mature females and 30 to 35 mature males were placed in 41 of seawater. The animals were monitored and forced to release their gametes into the water by gentle aspiration in a Pasteur pipette at full maturity. This was done to synchronize the population. After fertilization, embryos were transferred, using 11 beakers, into 2 fresh 61 beakers with the designated food regimes. After $24 \mathrm{~h}$, the content of each beaker was diluted into 3 new 61 beakers, and after an additional $24 \mathrm{~h}$, the contents of each of these beakers was in turn diluted into two 61 beakers, attaining a total of 12 beakers. These serial dilutions allowed addition of 
fresh seawater at $24 \mathrm{~h}$ intervals and promoted consistently better survival than 1, more extensive, initial dilution. After each dilution, the assigned food regime was added. Each successive $24 \mathrm{~h}$ after this, the animals were transferred with a $10 \mathrm{ml}$ Sterilin pipette with a cut tip, the diameter of which exceeded the maximum width of the house, to a fresh 61 beaker under the same experimental conditions.

Culture of animals for fatty acid analysis. Four experimental conditions were set up to investigate the fatty acid composition in Oikopleura dioica, given qualitatively and quantitatively different food regimes.

Different quality of algae: A generation of animals was split in 2 after hatching and 1 population was given a standard food regime of only Isochrysis sp., while the other received a standard food regime of only Chaetoceros calcitrans (Table 1). Animals from both food regimes were sampled (10 replicates) each $24 \mathrm{~h}$ after fertilization, and the fatty acid contents were analyzed. Fecal pellets from both food regimes were sampled (5 replicates) each $24 \mathrm{~h}$ starting $4 \mathrm{~d}$ after fertilization, and the fatty acid content analyzed. The number of animals and fecal pellets in each replicate varied with age (Table 2).

Different quantity of algae: A generation of animals was split in 2 after hatching and 1 population was given a standard food regime of both algae, while the other was given a limited food regime of both algae (Table 1). Animals and fecal pellets from both food regimes were sampled as in the above experiment.

Fatty acid analyses. Sampled animals were prodded to escape their house and left in fresh sterile-filtered sea water $(0.2 \mu \mathrm{m})$ for $15 \mathrm{~min}$. The animals were then inspected with a stereo microscope to confirm absence of fecal pellets in the stomach. Animals were transferred with a micropipette to a $1 \mathrm{ml}$ thick-walled glass vial with a conical bottom and a Teflon-lined screw cap. The number of animals for each replicate varied with the age of the animals (Table 2). A 1-step extraction-methylation procedure was used (Ulberth \& Henninger 1995). Residual water was evaporated under a stream of nitrogen gas. An internal standard

Table 1. Food regimes for quantitative and qualitative protocols

\begin{tabular}{|lcccc|}
\hline Protocol & Food regime & Algae $^{\mathrm{a}}$ & $\begin{array}{c}0-96 \mathrm{~h} \\
\left(\text { cells ml }^{-1}\right)\end{array}$ & $\begin{array}{c}96 \mathrm{~h} \text {-maturity } \\
(\text { cells ml }\end{array}$ \\
\hline Qualitative & Isochrysis & Isochrysis & 4000 & 8000 \\
Quantitative & Chaetoceros & Chaetoceros & 4000 & 8000 \\
& Standard & Isochrysis & 2000 & 4000 \\
& Limited & Chaetoceros & 2000 & 4000 \\
& Isochrysis & 333 & 666 \\
a Thaetoceros & 333 & 666 \\
& & Che algal strains used were Isochrysis sp. and Chaetoceros calcitrans \\
\hline
\end{tabular}

Table 2. Number of animals and fecal pellets per replicate fatty acid analysis

\begin{tabular}{|lcc|}
\hline Age $(\mathrm{d})$ & Animals & ${ }^{\mathrm{a} F e c a l}$ pellets \\
\hline 1 & 50 & - \\
2 & 40 & - \\
3 & 35 & - \\
4 & 8 & 80 \\
5 & 2 & 30 \\
6 (mature) & 1 & \\
aFecal pellets were not sampled at early stages because of \\
their small size
\end{tabular}

(0.12 $\mu \mathrm{g}, 19: 0$, NuChek Prep.) dissolved in chloroform was added to each sample and the solvent was evaporated under nitrogen. To methanolyze the fatty acids, $50 \mu \mathrm{l}$ of $2 \mathrm{M}$ dry methanolic- $\mathrm{HCl}$ was added, and the vial was capped and incubated at $90^{\circ} \mathrm{C}$ for $2 \mathrm{~h}$. The methanolic- $\mathrm{HCl}$ was evaporated with nitrogen gas and the remaining methyl esters were dissolved in $40 \mathrm{Hl}$ HPLC-grade hexane. Polar components were extracted with $20 \mu \mathrm{l}$ of $\mathrm{H}_{2} \mathrm{O}$. The samples were vortexed and placed at $-20^{\circ} \mathrm{C}$ until the polar portion was frozen. The non-polar hexane layer was transferred with a Hamilton pipette into a conical bottom crimptop GC microvial. Nitrogen gas was quickly purged over the samples to eliminate any oxygen in order to avoid oxidation of fatty acids, and the vial was capped. The methyl esters were then analyzed by gas chromatography (Hewlett Packard HP 5890 II with a HP 7673 A automatic injection system) as previously described (Grahl-Nielsen et al. 2003). Full results containing all fatty acids at all time points are given in Tables A to F of Appendix 1. Tables 3 to 7 reported in the text present average values for phases 2, 3 and 4 of the life cycle (Troedsson et al. 2002) of a subset of fatty acids. Phase 2 was defined from the expansion of the first house to when the reproductive organ started to grow. Phase 3 was defined from the start of reproductive organ growth until the beginning of spawning. Phase 4 was defined as mature animals with gametes nearing the time of release. Table 8 shows a subset of fatty acids in fecal pellets at 3 time points.

Net lipid accumulation efficiency. Net lipid accumulation efficiency was calculated using the quantity of fatty acids cleared from the given experimental environment and allocated to body mass. The total fatty acid quantity per cell of Isochrysis sp. or Chaetoceros calcitrans was analyzed using 19:0 (NuChek Prep.) as an internal standard. The number of cells cleared from the water column per time unit was cor- 
related to the food concentration according to Selander $\&$ Tiselius (2003). We used the same somatic size of animals as Selander \& Tiselius to avoid size effects (Broms $\&$ Tiselius 2003). The instantaneous net lipid accumulation efficiency $\left(\mathrm{NLAE}_{\mathrm{i}}\right)$ was calculated as the percentage of lipids assimilated and used for fatty acid increase:

$$
\mathrm{NLAE}_{\mathrm{i}}=\left[\mathrm{G}_{\text {animals }} /\left(\mathrm{IR}_{\mathrm{FA}}-\mathrm{P}_{\mathrm{FA}}\right)\right] \times 100
$$

where $G_{\text {animals }}$ (ng FA ind. ${ }^{-1} \mathrm{~h}^{-1}$ ) is the fatty acid increase in animals over $1 \mathrm{~h}, \mathrm{IR}_{\mathrm{FA}}$ (ng FA ind. ${ }^{-1} \mathrm{~h}^{-1}$ ) is the amount of fatty acids cleared from the water column in $1 \mathrm{~h}$, and $\mathrm{P}_{\mathrm{FA}}$ (ng FA ind $\mathrm{d}^{-1} \mathrm{~h}^{-1}$ ) is the amount of fatty acid that is excreted in fecal pellets in $1 \mathrm{~h} . \mathrm{P}_{\mathrm{FA}}$ is dependent on the number of pellets excreted per hour and we, therefore, used the gut passage time (GPT) estimated by López-Urrutia \& Acuña (1999):

$$
\mathrm{GPT}=51.67\left(\mathrm{FC}^{-0.245}\right) \times \mathrm{e}^{-0.0376 T}
$$

where FC represents the concentration of available

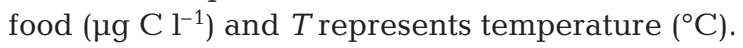

Statistical analysis. Chromatographic data were treated by multivariate statistics, using principal component analysis in the SIRIUS 6.5 package (Kvalheim \& Karstang 1987). Data were normalized by expressing the methyl esters as a percentage of the total amount in the sample. The percentages as well as the total quantity of fatty acids in the tables are given to 2 insignificant digits. The data were logarithmically transformed to avoid dominance of highly abundant methyl esters. The samples were placed in an $n$-dimensional space $(n=$ the number of methyl esters in the sample). Two new coordinates (principal components or PCs) were generated through the center of gravity, explaining the largest and the second largest variation in the samples. Twodimensional plots (PCs) were made from this analysis as a representation of the separation between samples.

Quantification of total fatty acids was calculated using 19:0 as an internal standard. Linear regression analysis of the population was performed with Statistix8. The data were log-transformed and a normality test (Shapiro-Wilks) and test of co-linearity were run to ensure requirements were fulfilled to perform a linear regression analysis. To investigate differences in a particular fatty acid quantity between 2 groups at a fixed time point, a $t$-test was performed after verification of homogeneity in the variance.

\section{RESULTS AND DISCUSSION}

The major fatty acids in Oikopleura dioica were myristic acid (14:0), palmitic acid (16:0), palmitoleic acid $(16: 1 \mathrm{n} 7)$, stearic acid (18:0), stearidonic acid (18:4n3), eicosapentaenoic acid (20:5n3 [EPA]) and docosahexaenoic acid (22:6n3 [DHA]), with 18:4n3, EPA and DHA seeming to be increasingly important as the reproductive organs started to grow (Phase 3; Troedsson et al. 2002) (Tables 3 to 6). Indeed, these fatty acids accumulated in mature animals (Table 7). Selective assimilation of some important fatty acids in O. dioica is apparent by looking at fecal pellet composition. The major fatty acids remaining in the fecal pellet were 14:0, 16:0,16:1n7 and 18:0, while 18:4n3, EPA and DHA were preferentially absorbed by the animals (Table 8 ). Synthesis of $18: 4 \mathrm{n} 3$ via $\alpha$-linolenic acid, catalyzed by $\delta$ - 6 -desaturase, is a starting point for further

Table 3. Isochrysis sp. and Oikopleura dioica. Fatty acid compositions of Isochrysis sp. and O. dioica fed a diet containing only Isochrysis sp. Mean fatty acid compositions in the 3 growth phases of $O$. dioica. The full data set with samples every $24 \mathrm{~h}$ is given in Table A of Appendix 1 (www.int-res. com/journals/suppl/troedsson_appendix.pdf). The major fatty acids are given as the percentage of total composition with standard deviation. Groups: percent proportion of 5 major

\begin{tabular}{|c|c|c|c|c|}
\hline \multirow{2}{*}{$\begin{array}{l}\text { Fatty } \\
\text { acid }\end{array}$} & \multirow{2}{*}{$\begin{array}{l}\text { Isochry- } \\
\text { sis sp. }\end{array}$} & \multicolumn{3}{|c|}{ Oikopleura dioica } \\
\hline & & Phase 2 & Phase 3 & Phase 4 \\
\hline $14: 0$ & $12.8 \pm 5.1$ & $5.6 \pm 0.9$ & $10.1 \pm 1.6$ & $9.1 \pm 0.7$ \\
\hline $14: 1 \mathrm{n} 5$ & $0.3 \pm 0.1^{b}$ & $0.7 \pm 0.4$ & $0.6 \pm 0.2$ & $0.4 \pm 0.2$ \\
\hline $16: 0$ & $8.2 \pm 1.5$ & $17.5 \pm 3.0$ & $15.6 \pm 1.9$ & $17.3 \pm 3.4$ \\
\hline $16: 1 n 7^{a}$ & $2.1 \pm 1.0^{\mathrm{b}}$ & $5.8 \pm 1.7$ & $10.5 \pm 1.5$ & $13.7 \pm 1.0$ \\
\hline $16: 2 \mathrm{n} 6^{\mathrm{a}}$ & $0.4 \pm 0.2^{b}$ & $1.6 \pm 0.4$ & $0.6 \pm 0.3$ & $0.3 \pm 0.1$ \\
\hline $17: 0$ & $0.1 \pm 0.0^{b}$ & $0.6 \pm 0.2$ & $0.6 \pm 0.1$ & $0.7 \pm 0.1$ \\
\hline $18: 0$ & $1.0 \pm 0.3^{b}$ & $7.9 \pm 1.8$ & $2.4 \pm 1.0$ & $2.8 \pm 1.2$ \\
\hline $18: 1 n 9^{a}$ & $5.9 \pm 1.7^{b}$ & $2.0 \pm 0.9$ & $0.9 \pm 0.8$ & $0.3 \pm 0.1$ \\
\hline $18: 1 n 7^{a}$ & $0.9 \pm 0.1^{b}$ & $5.2 \pm 2.1$ & $2.2 \pm 0.7$ & $2.4 \pm 0.5$ \\
\hline $18: 2 \mathrm{n} 6^{\mathrm{a}}$ & $4.3 \pm 2.6^{b}$ & $1.4 \pm 0.6$ & $1.8 \pm 0.3$ & $1.8 \pm 0.3$ \\
\hline $18: 2 \mathrm{n} 4^{\mathrm{a}}$ & $0.2 \pm 0.2^{b}$ & $2.0 \pm 0.7$ & $0.7 \pm 0.5$ & $0.4 \pm 0.2$ \\
\hline $18: 3 n 3^{a}$ & $3.3 \pm 1.8^{b}$ & $1.6 \pm 0.8$ & $3.0 \pm 0.6$ & $2.7 \pm 0.7$ \\
\hline $18: 4 n 3^{a}$ & $9.3 \pm 4.9^{b}$ & $1.6 \pm 0.6$ & $10.4 \pm 2.3$ & $9.1 \pm 3.4$ \\
\hline 18:5n1 & $0.6 \pm 0.2^{\mathrm{b}}$ & $2.8 \pm 1.0$ & $1.1 \pm 0.9$ & $0.5 \pm 0.4$ \\
\hline 20:1n9 & $0.4 \pm 0.2^{b}$ & $2.0 \pm 0.6$ & $0.6 \pm 0.2$ & $0.4 \pm 0.2$ \\
\hline $20: 2 \mathrm{n} 6$ & $0.2 \pm 0.2^{b}$ & $0.1 \pm 0.1$ & $0.1 \pm 0.0$ & $0.2 \pm 0.1$ \\
\hline $20: 4 \mathrm{n} 6$ & $0.2 \pm 0.1$ & $0.2 \pm 0.1$ & $0.6 \pm 0.2$ & $0.7 \pm 0.2$ \\
\hline $20: 3 n 3$ & $0.2 \pm 0.2^{\mathrm{b}}$ & $0.4 \pm 0.2$ & $0.3 \pm 0.2$ & $0.2 \pm 0.1$ \\
\hline $20: 5 n 3^{a}$ & $2.5 \pm 1.0^{\mathrm{b}}$ & $5.4 \pm 1.4$ & $8.6 \pm 0.9$ & $8.2 \pm 2.1$ \\
\hline $22: 0$ & $0.2 \pm 0.0^{\mathrm{b}}$ & $0.6 \pm 0.2$ & $0.2 \pm 0.1$ & $0.3 \pm 0.2$ \\
\hline $21: 5 n 3^{a}$ & $0.1 \pm 0.1^{b}$ & $1.2 \pm 0.4$ & $0.5 \pm 0.3$ & $0.4 \pm 0.2$ \\
\hline $22: 5 n 6^{a}$ & $1.2 \pm 0.3^{b}$ & $0.3 \pm 0.3$ & $1.5 \pm 0.4$ & $1.0 \pm 0.4$ \\
\hline $22: 5 n 3^{a}$ & $3.5 \pm 1.6$ & $1.8 \pm 0.7$ & $0.6 \pm 0.4$ & $0.3 \pm 0.2$ \\
\hline $24: 0^{\mathrm{a}}$ & $0.2 \pm 0.0$ & $0.6 \pm 0.2$ & $0.3 \pm 0.1$ & $0.2 \pm 0.1$ \\
\hline $22: 6 n 3^{a}$ & $6.9 \pm 4.3^{b}$ & $1.7 \pm 0.8$ & $7.7 \pm 1.7$ & $6.7 \pm 2.7$ \\
\hline \multicolumn{5}{|l|}{ Groups } \\
\hline SFA & $22.9 \pm 5.4$ & $35.4 \pm 5.4$ & $30.5 \pm 2.8$ & $31.6 \pm 3.7$ \\
\hline MUFA & $11.0 \pm 2.0$ & $17.1 \pm 3.4$ & $15.5 \pm 1.8$ & $17.5 \pm 1.2$ \\
\hline PUFA & $32.9 \pm 7.4$ & $22.2 \pm 4.4$ & $37.4 \pm 4.7$ & $32.4 \pm 4.9$ \\
\hline$n-3$ & $26.0 \pm 7.0$ & $13.7 \pm 3.4$ & $31.1 \pm 4.7$ & $27.6 \pm 4.9$ \\
\hline$n-6$ & $6.3 \pm 2.6$ & $3.6 \pm 0.8$ & $4.6 \pm 0.6$ & $4.0 \pm 0.4$ \\
\hline \multicolumn{5}{|c|}{$\begin{array}{l}\text { a Fatty acids showing a significant difference (regression } \\
\text { analysis: } \mathrm{p}<0.05 \text { ) between animals fed Isochrysis sp. com- } \\
\text { pared to Chaetoceros calcitrans throughout the life cycle }\end{array}$} \\
\hline \multicolumn{5}{|c|}{$\begin{array}{l}{ }^{\mathrm{b}} \text { Fatty acids that differ significantly }(t \text {-test: } \mathrm{p}<0.05 \text { ) from the } \\
\text { respective values for Chaetoceros calcitrans }(\text { Table } 4 \text { ) }\end{array}$} \\
\hline
\end{tabular}
groups of fatty acids 
Table 4. Chaetoceros calcitrans and Oikopleura dioica. Fatty acid compositions of C. calcitrans and $O$. dioica fed a diet containing only $C$. calcitrans. Mean fatty acid compositions in the 3 growth phases of $O$. dioica. The full data set with samples every $24 \mathrm{~h}$ is given in Table B of Appendix 1. The major fatty acids are given as the percentage of total composition with standard deviation. Groups: percent proportion of 5 major groups of fatty acids

\begin{tabular}{|c|c|c|c|c|}
\hline \multirow{2}{*}{$\begin{array}{l}\text { Fatty } \\
\text { acid }\end{array}$} & \multirow{2}{*}{$\begin{array}{l}\text { Chaetoceros } \\
\text { calcitrans }\end{array}$} & \multicolumn{3}{|c|}{ Oikopleura dioica } \\
\hline & & Phase 2 & Phase 3 & Phase 4 \\
\hline $14: 0$ & $9.2 \pm 6.7$ & $4.8 \pm 1.5$ & $9.2 \pm 2.9$ & $6.8 \pm 1.5$ \\
\hline 14:1n5 & $0.2 \pm 0.1^{\mathrm{b}}$ & $0.6 \pm 0.3$ & $0.7 \pm 0.1$ & $0.6 \pm 0.2$ \\
\hline 16:0 & $6.5 \pm 4.9^{\mathrm{b}}$ & $16.9 \pm 3.7$ & $15.4 \pm 2.7$ & $15.5 \pm 2.2$ \\
\hline $16: 1 \mathrm{n} 7^{\mathrm{a}}$ & $8.5 \pm 5.5^{\mathrm{b}}$ & $5.3 \pm 1.6$ & $14.5 \pm 4.1$ & $15.2 \pm 3.2$ \\
\hline $16: 2 \mathrm{n} 6^{\mathrm{a}}$ & $1.7 \pm 1.4^{\mathrm{b}}$ & $1.7 \pm 0.8$ & $0.5 \pm 0.5$ & $0.4 \pm 0.3$ \\
\hline $17: 0$ & $0.3 \pm 0.3^{b}$ & $0.6 \pm 0.2$ & $0.5 \pm 0.1$ & $0.7 \pm 0.2$ \\
\hline $18: 0$ & $1.9 \pm 1.4^{\mathrm{b}}$ & $8.4 \pm 1.7$ & $2.6 \pm 1.5$ & $2.6 \pm 0.9$ \\
\hline $18: 1 n 9^{a}$ & $0.3 \pm 0.4^{\mathrm{b}}$ & $2.5 \pm 1.7$ & $1.3 \pm 1.7$ & $1.1 \pm 0.9$ \\
\hline $18: 1 \mathrm{n} 7^{\mathrm{a}}$ & $0.3 \pm 0.1^{\mathrm{b}}$ & $5.2 \pm 2.4$ & $1.6 \pm 1.0$ & $1.6 \pm 0.5$ \\
\hline $18: 2 \mathrm{n} 6^{\mathrm{a}}$ & $0.3 \pm 0.2^{\mathrm{b}}$ & $1.3 \pm 0.4$ & $1.0 \pm 0.2$ & $1.2 \pm 0.2$ \\
\hline $18: 2 \mathrm{n} 4^{\mathrm{a}}$ & $0.4 \pm 0.1^{\mathrm{b}}$ & $2.3 \pm 1.3$ & $0.6 \pm 0.7$ & $1.0 \pm 1.0$ \\
\hline $18: 3 n 3^{a}$ & $0.1 \pm 0.1^{\mathrm{b}}$ & $1.6 \pm 0.8$ & $0.7 \pm 0.2$ & $1.1 \pm 0.2$ \\
\hline $18: 4 n 3^{a}$ & $0.2 \pm 0.1^{\mathrm{b}}$ & $1.3 \pm 0.7$ & $2.5 \pm 0.8$ & $4.6 \pm 1.2$ \\
\hline 18:5n1 & $1.3 \pm 0.5^{\mathrm{b}}$ & $3.2 \pm 2.0$ & $0.9 \pm 0.9$ & $1.3 \pm 1.2$ \\
\hline 20:1n9 & $0.1 \pm 0.0^{\mathrm{b}}$ & $2.2 \pm 1.0$ & $0.5 \pm 0.2$ & $0.4 \pm 0.1$ \\
\hline 20:2n6 & $0.5 \pm 0.3^{\mathrm{b}}$ & $0.1 \pm 0.1$ & $0.2 \pm 0.1$ & $0.2 \pm 0.1$ \\
\hline $20: 4 \mathrm{n} 6$ & $0.3 \pm 0.2$ & $0.2 \pm 0.1$ & $0.9 \pm 0.3$ & $0.5 \pm 0.1$ \\
\hline 20:3n3 & $0.5 \pm 0.3^{\mathrm{b}}$ & $0.4 \pm 0.2$ & $0.2 \pm 0.1$ & $0.2 \pm 0.1$ \\
\hline $20: 5 n 3^{a}$ & $6.5 \pm 3.1^{\mathrm{b}}$ & $5.9 \pm 1.2$ & $18.3 \pm 5.3$ & $9.9 \pm 2.3$ \\
\hline $22: 0$ & $1.1 \pm 0.5^{b}$ & $0.6 \pm 0.3$ & $0.3 \pm 0.1$ & $0.3 \pm 0.1$ \\
\hline $21: 5 n 3^{a}$ & $-^{\mathrm{b}}$ & $1.1 \pm 0.6$ & $0.5 \pm 0.4$ & $0.7 \pm 0.7$ \\
\hline $22: 5 n 6^{a}$ & $0.2 \pm 0.2^{\mathrm{b}}$ & $0.1 \pm 0.2$ & $0.2 \pm 0.1$ & $0.1 \pm 0.1$ \\
\hline $22: 5 n 3^{a}$ & $6.6 \pm 4.8$ & $1.6 \pm 0.9$ & $0.6 \pm 0.5$ & $0.5 \pm 0.4$ \\
\hline $24: 0^{\mathrm{a}}$ & $0.5 \pm 0.3$ & $0.6 \pm 0.3$ & $0.2 \pm 0.1$ & $0.2 \pm 0.1$ \\
\hline $22: 6 n 3^{a}$ & $0.3 \pm 0.1^{b}$ & $1.6 \pm 0.9$ & $4.0 \pm 0.9$ & $4.5 \pm 1.5$ \\
\hline \multicolumn{5}{|l|}{ Groups } \\
\hline SFA & $20.2 \pm 8.4$ & $35.4 \pm 5.4$ & $30.5 \pm 2.8$ & $27.5 \pm 2.8$ \\
\hline MUFA & $11.8 \pm 5.8$ & $17.3 \pm 3.3$ & $19.3 \pm 2.0$ & $19.1 \pm 2.3$ \\
\hline PUFA & $19.0 \pm 6.0$ & $22.4 \pm 4.4$ & $31.2 \pm 3.9$ & $26.2 \pm 3.5$ \\
\hline$n-3$ & $14.2 \pm 5.8$ & $13.6 \pm 3.0$ & $26.9 \pm 5.0$ & $21.5 \pm 3.1$ \\
\hline$n-6$ & $3.0 \pm 1.5$ & $3.3 \pm 0.8$ & $2.8 \pm 0.6$ & $2.3 \pm 0.4$ \\
\hline \multicolumn{5}{|c|}{$\begin{array}{l}\text { a Fatty acids showing a significant difference (regression } \\
\text { analysis: } \mathrm{p}<0.05 \text { ) between animals fed Isochrysis sp. com- } \\
\text { pared to Chaetoceros calcitrans throughout the life cycle }\end{array}$} \\
\hline \multicolumn{5}{|c|}{$\begin{array}{l}{ }^{b} \text { Fatty acids that differ significantly ( } t \text {-test: } \mathrm{p}<0.05 \text { ) from the } \\
\text { respective values for Isochrysis sp. (Table } 3 \text { ) }\end{array}$} \\
\hline
\end{tabular}

modification to key fatty acids in the endocrine regulatory system. One such key fatty acid, EPA, is an important constituent of phospholipids in all animal tissues, especially the brain, and is the precursor of the $\mathrm{PG}_{3}$ series of prostaglandins (Braden \& Carroll 1986, Harwood 1994). Another fatty acid in this pathway, DHA is enriched in brain synapses and heart tissue, and is thought to have important roles during neural development of larvae (Gunstone \& Herslof 2000, Valenzuela et al. 2004).

The fatty acid compositions of Isochrysis sp. and Chaetoceros calcitrans were significantly different from each other (Fig. 1), in general agreement with previous
Table 5. Oikopleura dioica. Fatty acid composition of $O$. dioica fed a standard food regime. Mean fatty acid compositions in the 3 growth phases of $O$. dioica. The full data set with samples every $24 \mathrm{~h}$ is given in Table $\mathrm{C}$ of Appendix 1. The major fatty acids are given as a percentage of total composition with standard deviation. Groups: percent proportion of 5 major groups of fatty acids

\begin{tabular}{|c|c|c|c|}
\hline \multirow{2}{*}{$\begin{array}{l}\text { Fatty } \\
\text { acid }\end{array}$} & \multicolumn{3}{|c|}{ Oikopleura dioica: standard food regime } \\
\hline & Phase 2 & Phase 3 & Phase 4 \\
\hline $14: 0^{\mathrm{a}}$ & $5.3 \pm 1.1$ & $9.0 \pm 2.1$ & $7.9 \pm 3.0$ \\
\hline $14: 1 \mathrm{n} 5^{\mathrm{a}}$ & $0.3 \pm 0.1$ & $0.1 \pm 0.1$ & $0.1 \pm 0.1$ \\
\hline $15: 0^{\mathrm{a}}$ & $1.5 \pm 0.3$ & $1.3 \pm 0.3$ & $1.3 \pm 0.4$ \\
\hline $16: 0^{\mathrm{a}}$ & $14.0 \pm 2.6$ & $16.1 \pm 2.3$ & $15.7 \pm 3.5$ \\
\hline $16: 1 n 7^{a}$ & $14.2 \pm 2.6$ & $16.3 \pm 2.4$ & $15.9 \pm 3.6$ \\
\hline $16: 2 \mathrm{n} 6^{\mathrm{a}}$ & $1.5 \pm 0.8$ & $0.8 \pm 0.4$ & $0.6 \pm 0.3$ \\
\hline $17: 0^{\mathrm{a}}$ & $0.5 \pm 0.1$ & $0.5 \pm 0.1$ & $0.5 \pm 0.2$ \\
\hline 18:0 & $4.3 \pm 1.2$ & $3.7 \pm 1.4$ & $2.3 \pm 0.9$ \\
\hline $18: 1 \mathrm{n} 7$ & $1.3 \pm 1.8$ & $2.4 \pm 1.3$ & $1.9 \pm 0.5$ \\
\hline $18: 2 \mathrm{n} 6^{\mathrm{a}}$ & $1.3 \pm 0.3$ & $1.4 \pm 0.3$ & $2.0 \pm 0.4$ \\
\hline $18: 2 \mathrm{n} 4^{\mathrm{a}}$ & $1.8 \pm 1.0$ & $0.8 \pm 0.6$ & $0.6 \pm 0.4$ \\
\hline $18: 3 n 3^{a}$ & $2.3 \pm 0.8$ & $2.2 \pm 0.7$ & $2.6 \pm 0.8$ \\
\hline $18: 4 n 3^{a}$ & $2.8 \pm 1.0$ & $6.1 \pm 2.0$ & $6.8 \pm 2.0$ \\
\hline 18:5n1 & $2.3 \pm 1.1$ & $1.3 \pm 0.9$ & $1.0 \pm 0.6$ \\
\hline $20: 0^{a}$ & $0.4 \pm 0.1$ & $0.4 \pm 0.1$ & $0.5 \pm 0.2$ \\
\hline $20: 1 n 9^{a}$ & $0.9 \pm 0.3$ & $0.6 \pm 0.2$ & $0.3 \pm 0.1$ \\
\hline $20: 4 n 6^{a}$ & $0.4 \pm 0.1$ & $0.4 \pm 0.1$ & $0.7 \pm 0.1$ \\
\hline $20: 5 n 3^{a}$ & $7.7 \pm 1.2$ & $7.2 \pm 1.9$ & $10.4 \pm 2.5$ \\
\hline $21: 5 n 3^{a}$ & $0.6 \pm 0.2$ & $1.1 \pm 0.4$ & $1.2 \pm 0.4$ \\
\hline $22: 5 n 6^{a}$ & $1.6 \pm 1.1$ & $0.9 \pm 0.8$ & $0.8 \pm 0.6$ \\
\hline $24: 0^{\mathrm{a}}$ & $0.4 \pm 0.2$ & $0.4 \pm 0.1$ & $0.3 \pm 0.1$ \\
\hline $22: 6 n 3^{a}$ & $5.7 \pm 1.8$ & $6.9 \pm 2.8$ & $8.0 \pm 2.6$ \\
\hline \multicolumn{4}{|l|}{ Groups } \\
\hline SFA & $26.8 \pm 4.5$ & $31.1 \pm 5.5$ & $28.0 \pm 4.7$ \\
\hline MUFA & $21.6 \pm 3.9$ & $22.7 \pm 5.6$ & $20.8 \pm 3.7$ \\
\hline PUFA & $33.0 \pm 4.0$ & $31.7 \pm 6.9$ & $37.0 \pm 4.4$ \\
\hline$n-3$ & $19.7 \pm 4.0$ & $23.4 \pm 7.3$ & $29.3 \pm 4.2$ \\
\hline$n-6$ & $4.8 \pm 1.5$ & $3.5 \pm 0.9$ & $4.3 \pm 0.8$ \\
\hline \multicolumn{4}{|c|}{$\begin{array}{l}{ }^{a} \text { Fatty acids showing a significant difference (regression } \\
\text { analysis: } p<0.05 \text { ) between animals fed a standard com- } \\
\text { pared to a limited food regime throughout the life cycle }\end{array}$} \\
\hline
\end{tabular}

studies (Napolitano et al. 1990). There were a number of differences between the 2 algae at the level of individual fatty acids, but the most striking differences were in 16:1n7, EPA, DHA and 18C fatty acids. Many of the 18C fatty acids, as well as 16:1n7, are common in a variety of organisms, and it is intriguing to see the higher percentage of 18:2n6 and 18:3n 3 in Isochrysis sp. ( $t$-test; 18:2n6 and 18:3n3, p < 0.001) (Tables $3 \& 4$ ). These fatty acids are rapidly metabolized in animals as they are metabolites of the n-3 and n- 6 family of essential fatty acids (Harwood 1994). The higher content of DHA in Isochrysis sp. and EPA in C. calcitrans is of interest as these fatty acids are known to be crucial for the development and survival of many marine animals (Støttrup \& Attramadal 1992, Koven et al. 1993, Kraul et al. 1993, Lochmann \& Gatlin 1993, Watanabe 1993, Whyte et al. 1994). The 2 algal species, thus, represent a characteristic nutritional difference between flagellates and diatoms, which might 
Table 6. Fatty acid composition of Oikopleura dioica fed a limited food regime. Mean fatty acid compositions in the 3 growth phases of $O$. dioica. The full data set with samples every $24 \mathrm{~h}$ is given in Table D of Appendix 1. The major fatty acids are given as a percentage of total composition with standard deviation. Groups: percent proportion of 5 major groups of fatty acids

\begin{tabular}{|c|c|c|c|}
\hline \multirow{2}{*}{$\begin{array}{l}\text { Fatty } \\
\text { acid }\end{array}$} & \multicolumn{3}{|c|}{ Oikopleura dioica: limited food regime } \\
\hline & Phase 2 & Phase 3 & Phase 4 \\
\hline $14: 0^{\mathrm{a}}$ & $4.6 \pm 1.1$ & $4.3 \pm 0.9$ & $4.1 \pm 0.9$ \\
\hline $14: 1 \mathrm{n} 5^{\mathrm{a}}$ & $0.3 \pm 0.2$ & $0.2 \pm 0.1$ & $0.2 \pm 0.1$ \\
\hline $15: 0^{\mathrm{a}}$ & $1.5 \pm 0.3$ & $1.3 \pm 0.5$ & $1.3 \pm 0.3$ \\
\hline $16: 0^{\mathrm{a}}$ & $15.4 \pm 2.9$ & $15.8 \pm 3.8$ & $16.5 \pm 2.7$ \\
\hline $16: 1 n 7^{a}$ & $15.6 \pm 3.0$ & $16.0 \pm 3.9$ & $16.8 \pm 2.7$ \\
\hline $16: 2 \mathrm{n} 6^{\mathrm{a}}$ & $1.3 \pm 0.7$ & $1.2 \pm 0.7$ & $0.8 \pm 0.5$ \\
\hline $17: 0^{\mathrm{a}}$ & $0.6 \pm 0.1$ & $0.6 \pm 0.2$ & $0.6 \pm 0.2$ \\
\hline $18: 0$ & $5.2 \pm 1.5$ & $5.1 \pm 2.2$ & $5.2 \pm 2.4$ \\
\hline $18: 1 \mathrm{n} 7$ & $2.0 \pm 1.8$ & $2.1 \pm 1.7$ & $2.8 \pm 0.8$ \\
\hline $18: 2 \mathrm{n} 6^{\mathrm{a}}$ & $1.2 \pm 0.3$ & $1.1 \pm 0.4$ & $1.6 \pm 0.6$ \\
\hline $18: 2 \mathrm{n} 4^{\mathrm{a}}$ & $1.5 \pm 0.9$ & $1.6 \pm 0.9$ & $0.6 \pm 0.7$ \\
\hline $18: 3 n 3^{a}$ & $2.0 \pm 1.0$ & $1.2 \pm 0.5$ & $1.7 \pm 0.9$ \\
\hline $18: 4 n 3^{a}$ & $2.0 \pm 0.6$ & $3.8 \pm 1.8$ & $5.5 \pm 3.0$ \\
\hline $18: 5 \mathrm{n} 1$ & $2.0 \pm 1.1$ & $2.2 \pm 1.0$ & $1.5 \pm 0.8$ \\
\hline $20: 0^{\mathrm{a}}$ & $0.5 \pm 0.1$ & $0.5 \pm 0.1$ & $0.8 \pm 0.2$ \\
\hline $20: 1 \mathrm{n} 9^{\mathrm{a}}$ & $1.2 \pm 0.3$ & $0.8 \pm 0.3$ & $1.2 \pm 0.5$ \\
\hline $20: 4 n 6^{\mathrm{a}}$ & $0.4 \pm 0.1$ & $0.3 \pm 0.1$ & $0.6 \pm 0.2$ \\
\hline $20: 5 n 3^{a}$ & $7.5 \pm 2.4$ & $6.7 \pm 2.2$ & $7.7 \pm 3.6$ \\
\hline $21: 5 n 3^{a}$ & $0.5 \pm 0.2$ & $0.5 \pm 0.3$ & $0.7 \pm 0.3$ \\
\hline $22: 5 n 6^{a}$ & $0.7 \pm 0.8$ & $1.7 \pm 1.0$ & $1.0 \pm 0.9$ \\
\hline $24: 0^{\mathrm{a}}$ & $0.5 \pm 0.2$ & $0.4 \pm 0.2$ & $0.3 \pm 0.1$ \\
\hline $22: 6 n 3^{a}$ & $4.9 \pm 2.0$ & $3.8 \pm 2.0$ & $5.4 \pm 2.6$ \\
\hline \multicolumn{4}{|l|}{ Groups } \\
\hline SFA & $28.7 \pm 5.4$ & $28.4 \pm 6.9$ & $29.1 \pm 3.7$ \\
\hline MUFA & $25.2 \pm 5.0$ & $23.8 \pm 3.6$ & $24.3 \pm 3.1$ \\
\hline PUFA & $28.4 \pm 5.5$ & $29.0 \pm 7.6$ & $32.3 \pm 7.7$ \\
\hline$n-3$ & $17.5 \pm 5.3$ & $16.7 \pm 6.2$ & $21.0 \pm 5.4$ \\
\hline$n-6$ & $3.6 \pm 1.1$ & $4.4 \pm 1.4$ & $4.1 \pm 1.2$ \\
\hline
\end{tabular}

affect animals experiencing higher levels of each of these types of algae at different times of the year. Indeed, there are scattered studies of appendicularian abundance (Uye \& Ichino 1995, Uye et al. 2000, Vargas et al. 2002, López-Urrutia et al. 2003, Tomita et al. 2003) that show peaks of Oikopleura density correlating with increased primary production, often beginning with a spring diatom bloom. However, although $O$. dioica clearly responds in its reproductive output to increased primary production (Troedsson et al. 2002), the regulation of Oikopleura population dynamics is more complex and also includes, for example, predation pressure, in addition to the quantity and quality of nutrition available.

The difference in fatty acid compositions of Isochrysis sp. and Chaetoceros calcitrans did indeed transfer into different compositions in Oikopleura dioica when fed a diet of only one or the other of these algae. Regression analysis on animals fed a diet of only

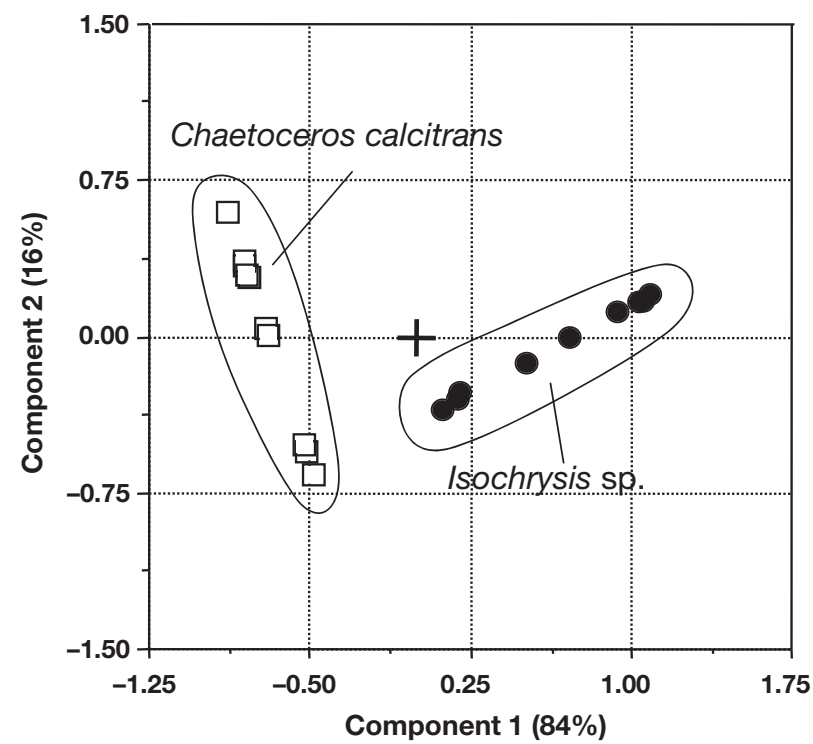

Fig. 1. Fatty acid compositions of algae. Two-dimensional principal component (2D-PC) plot of the fatty acid compositions of Isochrysis sp. (๑) and Chaetoceros calcitrans ( $\square$ ). The percentage of the total variation among the groups along the $2 \mathrm{PCs}$ is given on the respective axes. The symbols represent individual replicates. The 2 separated groups are circled

Isochrysis sp. or C. calcitrans did not show a significant difference $(\mathrm{p}[$ slope $]=0.3 ; \mathrm{p}$ [elevation $]=0.9)$ in total quantity of fatty acids throughout development (Fig. 2A). As seen in the PC plot (Fig. 2B), however, animals aged $3 \mathrm{~d}$ and older (Phase 3 ) showed a clear difference in fatty acid composition. Approximately $47 \%$ of all fatty acids (Tables $3 \& 4$, Tables A \& B in Appendix 1) showed a significant difference $(p<0.05)$ in a regression analysis. The 2 fatty acids characteristic of flagellates (DHA and 18:4n3) showed an increased level in $O$. dioica given only Isochrysis sp., while animals given only $C$. calcitrans had increased levels of EPA and 16:1n7, characteristic of diatom composition (Napolitano et al. 1990, Graeve et al. 1994, 1997, FalkPetersen et al. 1998, Scott et al. 1999). The 2 metabolites of the n-3 (18:3n3) and the n-6 (18:2n6) synthetic cascade showed a significant accumulation in animals fed Isochrysis sp. (18:3n3: p [slope] < 0.001, p[elevation] $<0.001 ; 18: 2 \mathrm{n} 6$ : p[slope] $=0.31$, p[elevation] $<0.001$ ) (Tables 3 \& 4). In Isochrysis sp., 18:2n6 and 18:3n3 represented 4.3 and $3.3 \%$, respectively, of the fatty acid pool. In contrast, C. calcitrans showed corresponding values of 0.3 and $0.1 \%$. These results agree with those found for herbivorous copepods (Graeve et al. 1997), the major component of marine zooplankton, where the fatty acid composition reflects that in the diet. The quality of microalgal fatty acid composition has been suggested to be more important for optimal growth and development than protein or carbohydrate compositions (Holland 1978, Webb \& Chu 1983). 
Table 7. Oikopleura dioica. Fatty acid compositions of $O$. dioica males and females under different dietary regimes. Composition of a subset of fatty acids from mature $O$. dioica. Full compositions are given in Table E of Appendix 1. Groups: percent proportion of 5 major groups of fatty acids

\begin{tabular}{|c|c|c|c|c|c|c|c|c|}
\hline \multirow{2}{*}{$\begin{array}{l}\text { Fatty } \\
\text { acid }\end{array}$} & \multicolumn{2}{|c|}{ Isochrysis sp. } & \multicolumn{2}{|c|}{ Chaetoceros calcitrans } & \multicolumn{2}{|c|}{ Standard } & \multicolumn{2}{|c|}{ Limited } \\
\hline & Male & Female & Male & Female & Male & Female & Male & Female \\
\hline 14:0 & $9.2 \pm 0.8$ & $9.0 \pm 0.7$ & $6.4 \pm 1.4$ & $7.2 \pm 1.8$ & $8.1 \pm 0.9$ & $8.8 \pm 0.9$ & $7.6 \pm 1.5$ & $7.4 \pm 0.3$ \\
\hline $16: 0$ & $20.5 \pm 0.9^{a}$ & $14.2 \pm 0.8$ & $16.8 \pm 2.2$ & $14.3 \pm 1.4$ & $15.0 \pm 1.7$ & $13.7 \pm 0.8$ & $18.5 \pm 1.8^{\mathrm{a}}$ & $14.7 \pm 0.7$ \\
\hline $16: 1 \mathrm{n} 7$ & $14.1 \pm 1.1$ & $13.3 \pm 0.7$ & $15.0 \pm 3.4$ & $15.3 \pm 3.3$ & $13.6 \pm 0.7^{\mathrm{a}}$ & $15.0 \pm 1.1$ & $15.3 \pm 1.7$ & $16.4 \pm 1.0$ \\
\hline $18: 0$ & $3.7 \pm 1.0^{\mathrm{a}}$ & $1.9 \pm 0.6$ & $3.0 \pm 1.0$ & $2.3 \pm 0.7$ & $2.6 \pm 0.3^{\mathrm{a}}$ & $1.7 \pm 0.2$ & $2.3 \pm 0.4^{\mathrm{a}}$ & $1.8 \pm 0.3$ \\
\hline $18: 1 \mathrm{n} 7$ & $2.8 \pm 0.3^{\mathrm{a}}$ & $2.0 \pm 0.3$ & $1.9 \pm 0.4^{\mathrm{a}}$ & $1.3 \pm 0.4$ & $1.9 \pm 0.3^{\mathrm{a}}$ & $1.4 \pm 0.1$ & $1.8 \pm 0.3^{\mathrm{a}}$ & $1.3 \pm 0.3$ \\
\hline $18: 2 \mathrm{n} 6$ & $1.5 \pm 0.5^{\mathrm{a}}$ & $2.1 \pm 0.1$ & $1.2 \pm 0.2$ & $1.2 \pm 0.2$ & $1.3 \pm 0.2^{\mathrm{a}}$ & $1.7 \pm 0.1$ & $1.4 \pm 0.1^{\mathrm{a}}$ & $1.6 \pm 0.1$ \\
\hline 18:3n3 & $2.1 \pm 0.5^{\mathrm{a}}$ & $3.3 \pm 0.2$ & $1.0 \pm 0.3$ & $1.2 \pm 0.1$ & $2.1 \pm 0.5^{\mathrm{a}}$ & $2.9 \pm 0.2$ & $1.7 \pm 0.2^{\mathrm{a}}$ & $2.3 \pm 0.3$ \\
\hline $18: 4 \mathrm{n} 3$ & $6.1 \pm 1.5^{\mathrm{a}}$ & $12.1 \pm 1.0$ & $3.9 \pm 1.3$ & $5.2 \pm 0.9$ & $6.3 \pm 1.4^{\mathrm{a}}$ & $11.0 \pm 0.9$ & $6.2 \pm 1.0^{\mathrm{a}}$ & $9.1 \pm 1.0$ \\
\hline $20: 1 \mathrm{n} 7$ & $0.1 \pm 0.1^{\mathrm{a}}$ & $0.2 \pm 0.0$ & $0.1 \pm 0.0$ & $0.1 \pm 0.0$ & $0.1 \pm 0.0^{\mathrm{a}}$ & $0.2 \pm 0.0$ & $0.1 \pm 0.0^{\mathrm{a}}$ & $0.2 \pm 0.0$ \\
\hline 20:4n6 & $0.5 \pm 0.1^{\mathrm{a}}$ & $0.8 \pm 0.1$ & $0.5 \pm 0.1$ & $0.5 \pm 0.1$ & $0.6 \pm 0.1$ & $0.7 \pm 0.1$ & $0.5 \pm 0.0$ & $0.6 \pm 0.1$ \\
\hline $20: 5 n 3$ & $6.5 \pm 1.5^{\mathrm{a}}$ & $9.9 \pm 0.5$ & $8.4 \pm 1.5^{\mathrm{a}}$ & $11.4 \pm 2.1$ & $8.1 \pm 1.3^{\mathrm{a}}$ & $11.0 \pm 1.3$ & $10.1 \pm 2.7$ & $12.3 \pm 1.1$ \\
\hline $22: 0$ & $0.1 \pm 0.1^{\mathrm{a}}$ & $0.5 \pm 0.1$ & $0.2 \pm 0.0^{\mathrm{a}}$ & $0.3 \pm 0.1$ & $0.2 \pm 0.1^{\mathrm{a}}$ & $0.4 \pm 0.1$ & $0.1 \pm 0.1^{\mathrm{a}}$ & $0.4 \pm 0.1$ \\
\hline $22: 5 \mathrm{n} 6$ & $0.7 \pm 0.2^{\mathrm{a}}$ & $1.4 \pm 0.3$ & $-^{\mathrm{a}}$ & $0.1 \pm 0.1$ & $0.6 \pm 0.1^{\mathrm{a}}$ & $0.8 \pm 0.1$ & $0.2 \pm 0.1^{\mathrm{a}}$ & $0.4 \pm 0.1$ \\
\hline $22: 6 n 3$ & $4.5 \pm 1.3^{\mathrm{a}}$ & $9.0 \pm 1.4$ & $3.5 \pm 1.1^{\mathrm{a}}$ & $5.5 \pm 1.2$ & $4.6 \pm 1.1^{\mathrm{a}}$ & $7.5 \pm 0.9$ & $5.6 \pm 0.9^{a}$ & $7.6 \pm 0.4$ \\
\hline \multicolumn{9}{|l|}{ Groups } \\
\hline SFA & $35.9 \pm 1.6^{\mathrm{a}}$ & $27.4 \pm 1.2$ & $28.7 \pm 2.8$ & $26.5 \pm 2.4$ & $27.9 \pm 2.0$ & $26.3 \pm 1.2$ & $30.5 \pm 2.4^{\mathrm{a}}$ & $26.3 \pm 0.8$ \\
\hline MUFA & $18.3 \pm 1.2^{\mathrm{a}}$ & $16.6 \pm 0.8$ & $19.3 \pm 3.6$ & $18.8 \pm 3.4$ & $17.9 \pm 1.1$ & $17.9 \pm 1.3$ & $18.6 \pm 1.7$ & $19.4 \pm 1.1$ \\
\hline PUFA & $25.1 \pm 2.7^{\mathrm{a}}$ & $40.2 \pm 1.9$ & $25 \pm 3.2$ & $28.8 \pm 2.8$ & $29.6 \pm 2.6^{a}$ & $37.4 \pm 1.9$ & $29.0 \pm 3.2$ & $35.7 \pm 1.6$ \\
\hline$n-3$ & $20.2 \pm 2.6^{\mathrm{a}}$ & $34.9 \pm 1.8$ & $18.7 \pm 2.5^{\mathrm{a}}$ & $24.3 \pm 2.6$ & $22.8 \pm 2.3^{\mathrm{a}}$ & $32.9 \pm 1.8$ & $24.9 \pm 3.1^{\mathrm{a}}$ & $31.8 \pm 1.6$ \\
\hline$n-6$ & $3.4 \pm 0.6^{\mathrm{a}}$ & $4.6 \pm 0.3$ & $3.1 \pm 0.4$ & $3.5 \pm 0.4$ & $2.7 \pm 0.3$ & $2.9 \pm 0.2$ & $2.4 \pm 0.2^{\mathrm{a}}$ & $2.3 \pm 0.2$ \\
\hline
\end{tabular}

Fig. 2. Oikopleura dioica. Fatty acid compositions of O. dioica fed diets differing in quality of nutrition. (A) Logtransformed plot of total fatty acid content per individual $O$. dioica throughout the life cycle when animals were fed a standard food concentration diet of only Isochrysis sp. (-) versus a diet of only Chaetoceros calcitrans ( $\square$ ). Regression parameters are given and standard deviations are indicated by bars. (B) Twodimensional principal component (2D-PC) plots of representative time points sampling fatty acid composition during phases 2, 3 and 4 (Troedsson et al. 2002) of $O$. dioica growth. The animals were separated into 2 groups after hatching and fed a diet of standard food concentration of Isochrysis sp. (•) or C. calcitrans ( $\square$ ). The percentage of the total variation among the groups along the 2 $\mathrm{PCs}$ is given on the respective axes. The symbols represent individual replicates. The 2 groups are circled
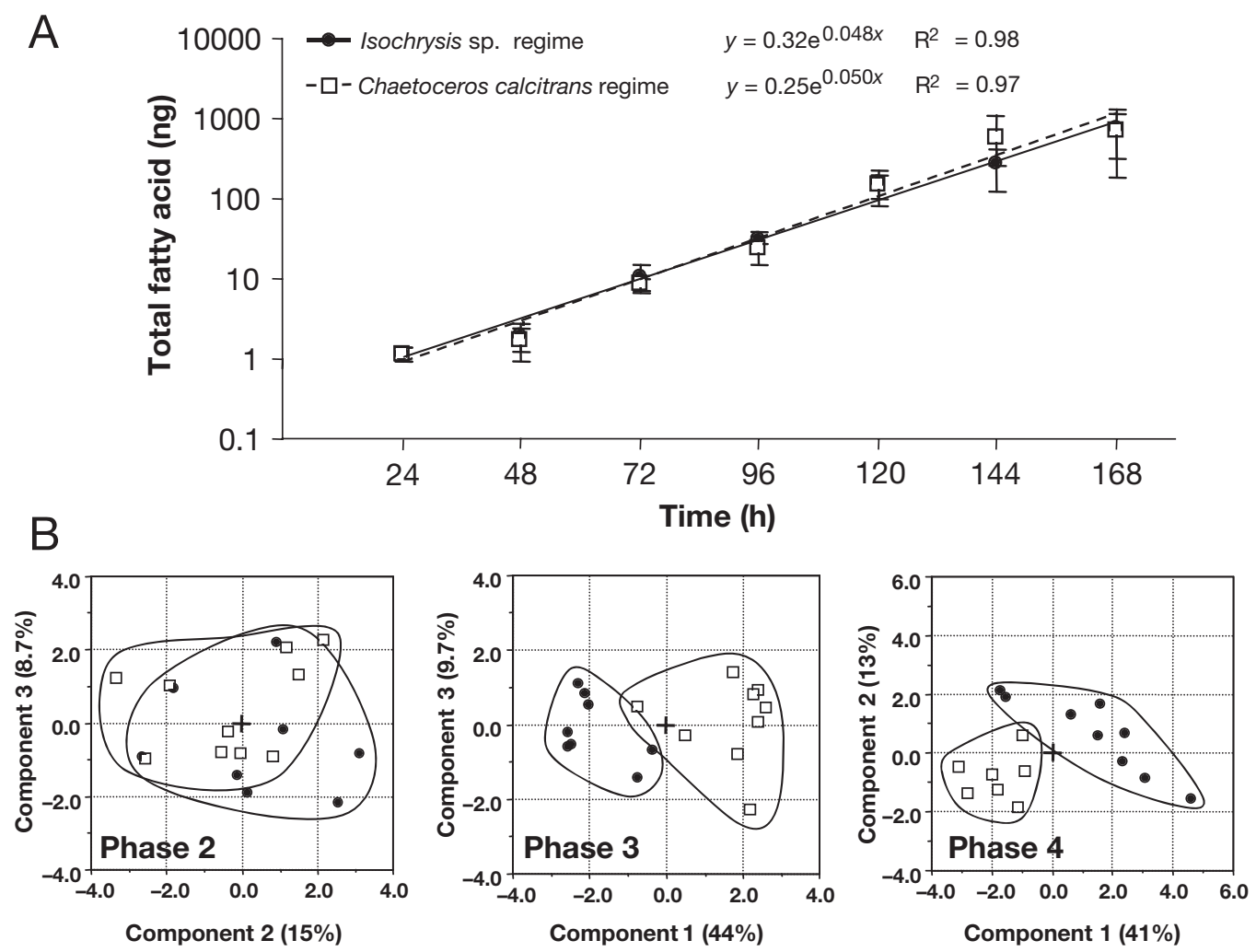

Isochrysis sp. regime

$\square$ Chaetoceros calcitrans regime 
Table 8. Oikopleura dioica. Fatty acid composition of $O$. dioica fecal pellets under different dietary regimes. The major fatty acids are given as a percentage of total composition with standard deviation of the fecal pellets at the specified times. Full fatty acid compositions of fecal pellets are given in Table F of Appendix 1. Groups: percent proportion of 5 major groups of fatty acids

\begin{tabular}{|c|c|c|c|c|c|c|c|c|c|c|}
\hline \multirow{3}{*}{$\begin{array}{l}\text { Fatty } \\
\text { acid }\end{array}$} & \multicolumn{4}{|c|}{ Qualitative diet } & \multicolumn{6}{|c|}{ Quantitative diet } \\
\hline & \multicolumn{2}{|c|}{ Isochrysis sp. } & \multicolumn{2}{|c|}{ Chaetoceros calcitrans } & \multirow[b]{2}{*}{$112 \mathrm{~h}$} & \multirow{2}{*}{$\begin{array}{c}\text {-Standard - } \\
136 \mathrm{~h}\end{array}$} & {[} & \multirow{2}{*}{$112 \mathrm{~h}$} & \multirow{2}{*}{$\begin{array}{c}\text { - Limited } \\
136 \mathrm{~h}\end{array}$} & \multirow[b]{2}{*}{$160 \mathrm{~h}$} \\
\hline & $96 \mathrm{~h}$ & $144 \mathrm{~h}$ & $96 \mathrm{~h}$ & $144 \mathrm{~h}$ & & & $160 \mathrm{~h}$ & & & \\
\hline $14: 0$ & $5.7 \pm 1.7$ & $7.1 \pm 0.8$ & $4.2 \pm 1.5$ & $2.2 \pm 0.6$ & $4.4 \pm 1.5$ & $7.3 \pm 2.6$ & $4.4 \pm 1.5$ & $1.8 \pm 0.6$ & $2.7 \pm 1.0$ & $2.8 \pm 0.8$ \\
\hline $14: 1 \mathrm{n} 5$ & $0.7 \pm 0.3$ & $0.7 \pm 0.4$ & $1.2 \pm 0.4$ & $0.9 \pm 0.6$ & $0.3 \pm 0.1$ & $0.3 \pm 0.1$ & $0.3 \pm 0.1$ & $0.3 \pm 0.1$ & $0.3 \pm 0.2$ & $0.4 \pm 0.2$ \\
\hline $15: 0$ & $2.3 \pm 0.3$ & $1.8 \pm 0.4$ & $1.9 \pm 0.6$ & $1.6 \pm 0.7$ & $1.2 \pm 0.6$ & $1.6 \pm 0.2$ & $1.8 \pm 0.7$ & $0.8 \pm 0.4$ & $1.4 \pm 0.4$ & $1.7 \pm 0.6$ \\
\hline $16: 0$ & $25.2 \pm 3.2$ & $19.0 \pm 2.2$ & $19.9 \pm 7.7$ & $13.3 \pm 4.8$ & $15.2 \pm 4.4$ & $22.2 \pm 3.9$ & $16.7 \pm 4.5$ & $11.1 \pm 3.1$ & $16.5 \pm 3.5$ & $18.6 \pm 3.5$ \\
\hline $16: 1 \mathrm{n} 7$ & $3.4 \pm 1.1$ & $2.4 \pm 0.6$ & $4.7 \pm 3.0$ & $2.0 \pm 0.7$ & $10 \pm 11$ & $4.2 \pm 2.1$ & $3.1 \pm 1.6$ & $1.7 \pm 0.8$ & $15.4 \pm 4.5$ & $2.3 \pm 1.7$ \\
\hline $16: 2 \mathrm{n} 6$ & $1.5 \pm 0.6$ & $1.1 \pm 0.8$ & $1.7 \pm 0.9$ & $0.9 \pm 0.4$ & $0.5 \pm 0.5$ & $0.3 \pm 0.6$ & $2.4 \pm 0.5$ & - & - & - \\
\hline $17: 0$ & $0.6 \pm 0.4$ & $0.5 \pm 0.2$ & $0.7 \pm 0.3$ & $0.4 \pm 0.3$ & $0.8 \pm 0.2$ & $1.1 \pm 0.3$ & $1.1 \pm 0.3$ & $0.7 \pm 0.3$ & $0.9 \pm 0.3$ & $1.2 \pm 0.3$ \\
\hline $18: 0$ & $13.5 \pm 1.0$ & $10.4 \pm 1.3$ & $8.6 \pm 3.0$ & $10.2 \pm 3.3$ & $9.1 \pm 2.3$ & $14.4 \pm 5.6$ & $8.8 \pm 1.9$ & $8.1 \pm 1.9$ & $10.5 \pm 2.4$ & $13.4 \pm 2.8$ \\
\hline $18: 1 \mathrm{n} 9$ & $2.3 \pm 0.9$ & $1.8 \pm 0.6$ & $4.2 \pm 2.6$ & $3.5 \pm 2.8$ & $3.7 \pm 1.8$ & $2.6 \pm 1.4$ & $4.7 \pm 1.5$ & $6.5 \pm 1.2$ & $6.8 \pm 1.8$ & $3.4 \pm 1.3$ \\
\hline $18: 1 \mathrm{n} 7$ & $5.3 \pm 3.0$ & $5.3 \pm 1.5$ & $3.4 \pm 3.7$ & $3.9 \pm 3.6$ & $4.5 \pm 1.3$ & $3.9 \pm 0.8$ & $5.2 \pm 1.5$ & $2.2 \pm 1.5$ & $2.9 \pm 2.2$ & $5.8 \pm 1.8$ \\
\hline $18: 2 \mathrm{n} 6$ & $0.8 \pm 0.4$ & $0.6 \pm 0.3$ & $0.6 \pm 0.3$ & $0.7 \pm 0.6$ & $0.8 \pm 0.2$ & $0.3 \pm 0.3$ & $0.5 \pm 0.2$ & $0.2 \pm 0.2$ & $0.2 \pm 0.2$ & $0.3 \pm 0.1$ \\
\hline $18: 2 \mathrm{n} 4$ & $2.2 \pm 0.6$ & $2.1 \pm 0.5$ & $3.3 \pm 1.6$ & $1.4 \pm 0.9$ & $1.3 \pm 1.6$ & $0.4 \pm 0.8$ & - & $3.6 \pm 0.7$ & $2.8 \pm 0.8$ & $1.0 \pm 1.4$ \\
\hline $18: 3 n 3$ & $0.5 \pm 0.1$ & $0.5 \pm 0.2$ & $0.3 \pm 0.1$ & $0.3 \pm 0.1$ & $0.6 \pm 0.3$ & $0.3 \pm 0.1$ & $0.3 \pm 0.1$ & $0.2 \pm 0.1$ & $0.2 \pm 0.2$ & $0.2 \pm 0.2$ \\
\hline $18: 4 \mathrm{n} 3$ & $0.2 \pm 0.3$ & $1.3 \pm 0.5$ & - & $0.9 \pm 0.3$ & $1.5 \pm 0.4$ & $0.2 \pm 0.2$ & - & $0.1 \pm 0.1$ & $0.1 \pm 0.2$ & $0.2 \pm 0.3$ \\
\hline $18: 5 n 1$ & $2.8 \pm 0.6$ & $3.9 \pm 1.0$ & $3.8 \pm 2.0$ & $4.9 \pm 1.8$ & $2.8 \pm 2.0$ & $2.1 \pm 0.8$ & $4.6 \pm 0.8$ & $4.7 \pm 1.2$ & $3.6 \pm 1.3$ & $3.3 \pm 1.1$ \\
\hline $20: 0$ & $0.7 \pm 0.4$ & $0.7 \pm 0.7$ & $0.6 \pm 0.2$ & $0.7 \pm 0.9$ & $0.5 \pm 0.2$ & $0.8 \pm 0.2$ & $1.0 \pm 0.3$ & $0.4 \pm 0.1$ & $0.6 \pm 0.2$ & $0.9 \pm 0.2$ \\
\hline 20:1n9 & $2.1 \pm 1.2$ & $2.2 \pm 1.0$ & $2.0 \pm 0.9$ & $4.5 \pm 3.4$ & $1.5 \pm 0.6$ & $1.9 \pm 1.0$ & $0.9 \pm 1.1$ & $1.7 \pm 0.5$ & $1.9 \pm 0.5$ & $2.3 \pm 0.5$ \\
\hline $20: 4 n 6$ & $0.2 \pm 0.2$ & $0.1 \pm 0.1$ & $0.1 \pm 0.1$ & - & $0.1 \pm 0.3$ & $0.2 \pm 0.2$ & $0.2 \pm 0.2$ & - & - & $0.3 \pm 0.4$ \\
\hline $20: 3 n 3$ & $0.6 \pm 0.8$ & $0.6 \pm 0.3$ & $0.3 \pm 0.4$ & $0.5 \pm 0.3$ & $0.7 \pm 0.4$ & $0.5 \pm 0.7$ & - & $0.8 \pm 0.2$ & $1.1 \pm 0.2$ & $0.4 \pm 0.4$ \\
\hline $20: 5 \mathrm{n} 3$ & $2.7 \pm 0.8$ & $3.1 \pm 1.8$ & $3.2 \pm 1.8$ & $4.9 \pm 1.3$ & $1.9 \pm 1.9$ & $1.1 \pm 1.5$ & $0.3 \pm 0.4$ & $4.4 \pm 1.4$ & $3.4 \pm 1.0$ & $2.2 \pm 2.1$ \\
\hline $22: 0$ & - & $0.4 \pm 0.4$ & $0.1 \pm 0.2$ & $0.4 \pm 0.2$ & $0.3 \pm 0.2$ & $0.3 \pm 0.4$ & $0.1 \pm 0.2$ & $0.3 \pm 1.0$ & $0.5 \pm 0.2$ & $0.3 \pm 0.3$ \\
\hline $21: 5 \mathrm{n} 3$ & - & $1.1 \pm 1.0$ & $0.4 \pm 0.9$ & $0.7 \pm 1.0$ & $0.3 \pm 0.2$ & $0.5 \pm 0.2$ & $0.2 \pm 0.4$ & $0.2 \pm 0.1$ & $0.3 \pm 0.2$ & $0.4 \pm 0.3$ \\
\hline $22: 5 \mathrm{n} 6$ & - & $0.1 \pm 0.1$ & $0.1 \pm 0.2$ & $0.2 \pm 0.2$ & $1.4 \pm 1.6$ & $0.8 \pm 1.0$ & $0.1 \pm 0.1$ & $3.5 \pm 1.3$ & $2.6 \pm 1.4$ & $1.3 \pm 1.4$ \\
\hline $24: 0$ & - & $0.7 \pm 0.9$ & $0.1 \pm 0.3$ & $0.2 \pm 0.3$ & $0.5 \pm 0.4$ & $0.4 \pm 0.5$ & - & $0.5 \pm 0.3$ & $0.8 \pm 0.5$ & $0.5 \pm 0.5$ \\
\hline $22: 6 \mathrm{n} 3$ & $1.1 \pm 0.4$ & $0.3 \pm 0.3$ & $0.6 \pm 0.5$ & $0.2 \pm 0.2$ & $0.9 \pm 0.4$ & $0.8 \pm 0.6$ & $3.3 \pm 0.8$ & - & - & $1.1 \pm 1.5$ \\
\hline \multicolumn{11}{|l|}{ Groups } \\
\hline SFA & $48.1 \pm 3.8$ & $40.4 \pm 3.0$ & $36 \pm 8.4$ & $29 \pm 6.0$ & $32.1 \pm 5.2$ & $48 \pm 7.3$ & $33.9 \pm 5.2$ & $23.6 \pm 3.9$ & $33.9 \pm 4.4$ & $39.5 \pm 4.6$ \\
\hline MUFA & $15.3 \pm 3.8$ & $14.4 \pm 2.5$ & $17 \pm 5.7$ & $16 \pm 5.9$ & $27 \pm 11$ & $20 \pm 3.2$ & $15.4 \pm 2.9$ & $14.1 \pm 2.2$ & $18.2 \pm 5.6$ & $18.6 \pm 3.2$ \\
\hline PUFA & $14.4 \pm 1.7$ & $17.0 \pm 2.9$ & $17 \pm 3.6$ & $18.4 \pm 3.3$ & $17 \pm 4.5$ & $10.1 \pm 2.8$ & $18.1 \pm 2.3$ & $26.2 \pm 2.7$ & $20.3 \pm 2.9$ & $16 \pm 4.1$ \\
\hline$n-3$ & $5.1 \pm 1.2$ & $8.2 \pm 2.5$ & $5.2 \pm 2.3$ & $8.7 \pm 2.5$ & $6.0 \pm 2.1$ & $3.4 \pm 1.8$ & $4.2 \pm 1.0$ & $5.9 \pm 1.4$ & $5.2 \pm 1.1$ & $4.4 \pm 2.7$ \\
\hline$n-6$ & $2.5 \pm 0.7$ & $1.9 \pm 0.9$ & $2.6 \pm 1.0$ & $1.8 \pm 0.7$ & $2.8 \pm 1.7$ & $1.6 \pm 1.2$ & $5.2 \pm 1.6$ & $3.7 \pm 1.3$ & $2.8 \pm 1.4$ & $2.4 \pm 1.8$ \\
\hline
\end{tabular}

Table 9. Instantaneous net lipid accumulation efficiency $\left(\mathrm{NLAE}_{\mathrm{i}}\right)$ under standard and limited food conditions. $\mathrm{IR}_{\mathrm{FA}}$ : fatty acids cleared from the water in $1 \mathrm{~h} ; \Delta \mathrm{G}_{\text {animals: }}$. net growth of soma and gonad fatty acid during $1 h_{i} P_{F A}$ : fatty acids excreted as fecal pellets in $1 \mathrm{~h}$. Further details are given in 'Materials and methods'

\begin{tabular}{|lcccc|}
\hline $\begin{array}{l}\text { Food } \\
\text { regime }\end{array}$ & $\begin{array}{c}\mathrm{IR}_{\mathrm{FA}} \\
\left(\mathrm{ng} \mathrm{FA} \mathrm{h}^{-1}\right)\end{array}$ & $\begin{array}{c}\Delta \mathrm{G}_{\text {animals }} \\
\left(\mathrm{ng} \mathrm{FA} \mathrm{h}^{-1}\right)\end{array}$ & $\begin{array}{c}\mathrm{P}_{\mathrm{FA}} \\
\left(\mathrm{ng} \mathrm{FA} \mathrm{h}^{-1}\right)\end{array}$ & $\begin{array}{c}\text { NLAE } \\
(\%)\end{array}$ \\
\hline Standard & 12.6 & 1.0 & 2.8 & 10.0 \\
Limited & 3.9 & 0.6 & 2.0 & 32.0 \\
\hline
\end{tabular}

The qualitative differences in appendicularians grazing on different food sources might influence growth and survival rates in organisms that prey on appendicularians. In marine species, the conversion of EPA to DHA is very limited (Kanazawa 1985), and it has been reported that DHA is superior to EPA as an essential fatty acid for growth and survival in marine fish larvae (Watanabe 1993). Indeed, the DHA level of appendic- ularians is significantly reduced when given a DHApoor nutrient. Furthermore, there was a difference between individual fatty acids in animals fed Isochrysis sp. versus Chaetoceros calcitrans that correlated with the fatty acid differences in the algae (Tables $3 \&$ 4 ), suggesting that Oikopleura, which transfers energy from micro-algae to fish, can also mediate nutritional value between trophic levels.

A regression analysis on animals fed a standard versus a limited food regime revealed significant differences $(\mathrm{p}[$ slope $]=0.18$; $\mathrm{p}$ [elevation $]<0.05)$ in their respective total quantities of fatty acids throughout development (Fig. 3A). The 2 groups clearly separated in the multivariate analysis (Fig. 3B, Tables 5 \& 6), where $66 \%$ of all fatty acids showed significant differences $(p<0.05)$. Separation between the 2 groups was observed continuously throughout the life cycle, and males separated from females at maturity (Fig. 4). The total fatty acid difference between animals fed standard and limited diets reflects the total body mass dif- 
Fig. 3. Oikopleura dioica. Fatty acid compositions of $O$. dioica fed diets differing in quantity of nutrition. (A) Log-transformed plot of total fatty acid content per individual $O$. dioica throughout the life cycle when animals were fed a standard $(\bullet)$ versus a limited $(\square)$ food regime. Regression parameters are given and standard deviations are indicated by bars. (B) Two-dimensional principal component (2D-PC) plots of representative time points sampling fatty acid composition during phases 2, 3 and 4 of $O$. dioica growth. The animals were separated into 2 groups after hatching and fed a standard $(\bullet)$ or limited ( $\square$ ) diet. The percentage of the total variation among the groups along the 2 PCs is given on the respective axes. The symbols represent individual replicates. The 2 groups are circled
A
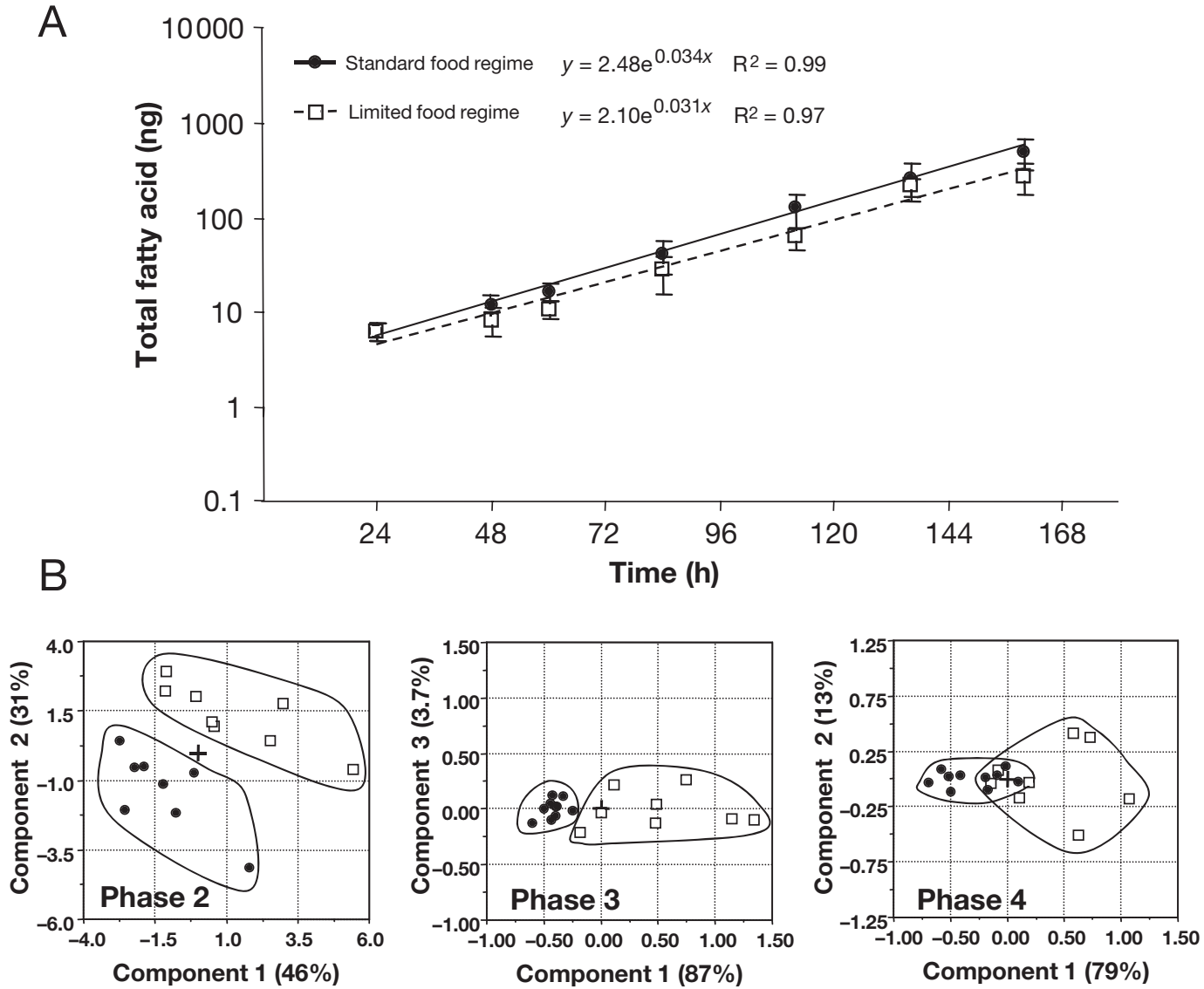

- Standard food regime $\square$ Limited food regime ferences resulting from the 2 regimes. The body mass difference in animals given a standard versus limited food regime was previously shown to reflect differences in reproductive output, as somatic growth appeared non-responsive to increased nutrition available (Troedsson et al. 2002). However, there was a difference ( $t$-test, $\mathrm{p}<0.05$ ) in the total fatty acid quantities as early as $48 \mathrm{~h}$ post-fertilization, well before the reproductive organ showed significant growth. A possible explanation for increased fatty acid content during somatic growth is that Oikopleura dioica stores fatty acids as high-energy droplets. Indeed, Cima et al. (2002) showed that lipid storage occurs in the form of droplets, mainly in the right gastric lobe and vertical intestine. These droplets would have a minimal impact on overall trunk size, but would enhance survival and reproductive output.

The fatty acid composition in Oikopleura dioica was also sex-dependent. In a principal component analysis, the males and females were clearly separated from each other when either the quality or quantity of the food regimes was modified (Fig. 4). In females, there was a significant increase in some essential fatty acids required for larval growth and development (Table 7).
Together with EPA and DHA, 18:3n3 and 18:2n6 were significantly up-regulated in females compared to males. Considering that at maturity the gonad accounts for $\sim 50 \%$ of the total body size of the organism, this indicates storage of these essential fatty acids in oocytes, providing nutrition for larvae throughout organogenesis up to metamorphosis when the animal starts to actively feed. In females, the up-regulation of EPA and DHA was noteworthy (Table 7) because both are important in subsequent larval development.

Although animals experiencing the limited regime were restricted to a diet only $17 \%$ of the standard food regime, the total fatty acid content of individual fecal pellets did not show any significant difference $(\mathrm{p}$ [slope $]=0.19 ; \mathrm{p}$ [elevation] $=0.57)($ Fig. 5A). This agrees with the observation of López-Urrutia \& Acuña (1999) that pellets are packed in the foregut, which empties as soon as pellets are formed. Pellets are then further transported through the digestive tract, and will therefore each contain the same quantity of food. On the other hand, they showed that gut passage time (GPT) varied with food concentration. This implies that the amount of fatty acids in excreted fecal pellets is independent of the quantity of food available for inges- 

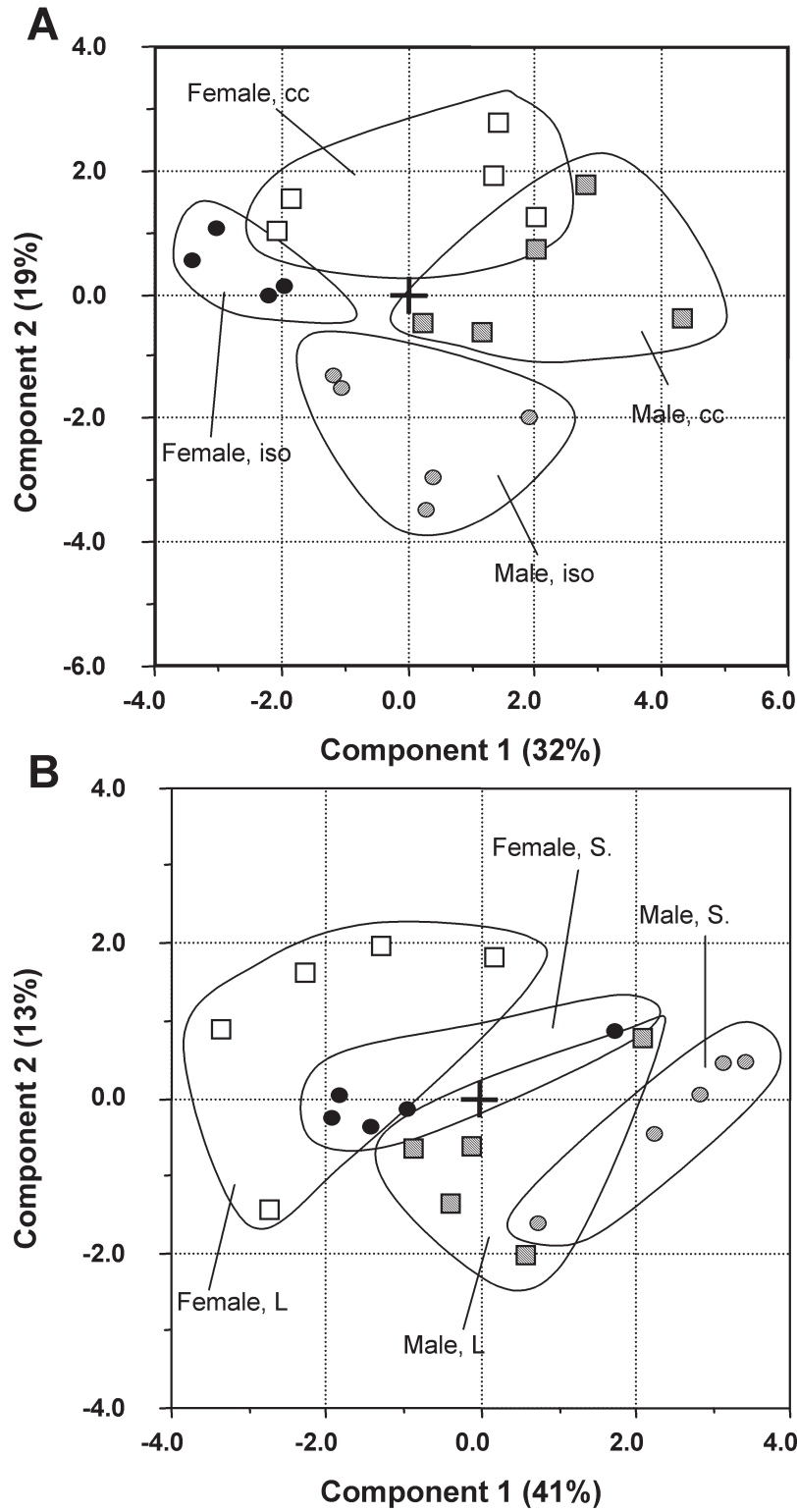

Fig. 4. Oikopleura dioica. Fatty acid compositions differ in $O$. dioica males and females. Two-dimensional principal component (2D-PC) plots of sexually mature animals. Plots show males and females in the respective food regimes. (A) Mature animals fed a diet of only Isochrysis sp. (iso) or only Chaetoceros calcitrans (cc). (B) Mature animals fed a standard (S) or limited food regime (L). Symbols represent individual replicates of mature animals. The sex as well as food regime groups are circled

tion. It is instead the slower gut passage time that results in lower total excretion of fatty acids when food is scarce (Fig. 5B).

There was an apparent 3-fold difference in the net lipid accumulation efficiency (NLAE) of Oikopleura dioica in the standard versus limited food regime (Table 9). Possible explanations include (1) changes in animal behavior, some of which are linked to clearance
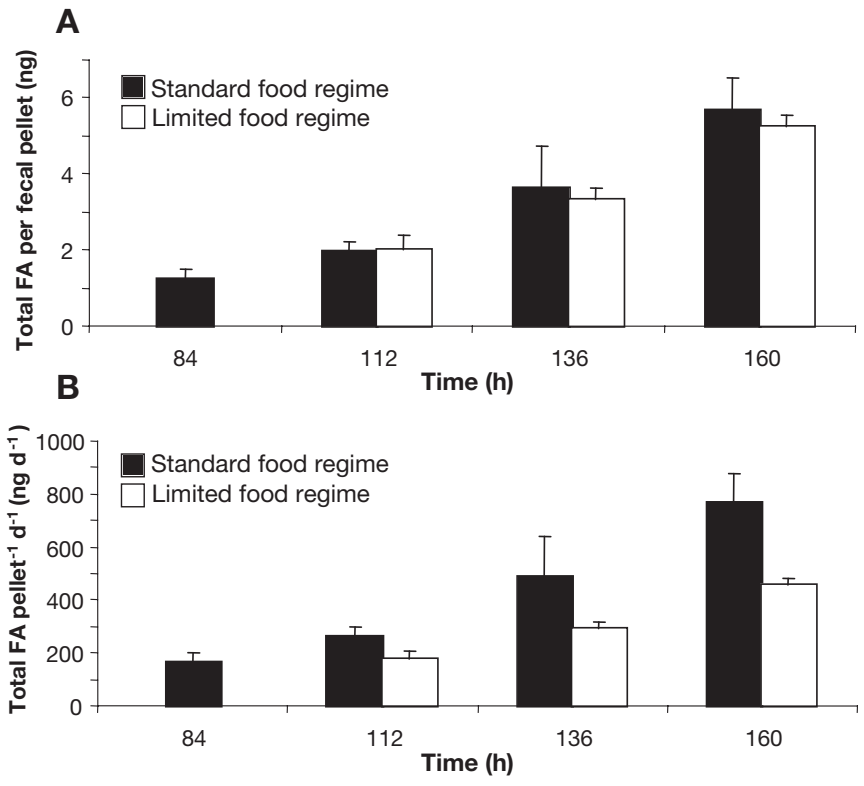

Fig. 5. Oikopleura dioica. Fatty acid (FA) content of fecal pellets throughout the life cycle of $O$. dioica. (A) Total quantity of FA per fecal pellet from $84 \mathrm{~h}$ (standard) and $112 \mathrm{~h}$ (limited) to maturation. Dark bars: fecal pellets from animals fed a standard food regime. White bars: fecal pellets from animals fed a limited food regime. (B) Total quantity of FA in fecal pellets over $24 \mathrm{~h}$ periods from $84 \mathrm{~h}$ (standard) and $112 \mathrm{~h}$ (limited) to maturation. Dark and white bars as in (A). Standard deviations are indicated

rate $(\mathrm{CR})$ (e.g. tail beat frequency and tail beat arrest), (2) increased clogging of filters with increasing food concentration, (3) plasticity of filter structure in response to altered food concentrations. Several studies have shown a nearly fixed $\mathrm{CR}$ for $O$. dioica, with only slight changes over very large ranges of food concentrations (Paffenhöfer 1975, King 1982, Bochdansky \& Deibel 1999, Acuña \& Kiefer 2000). Bochdansky \& Deibel (1999) found that feeding effort was reduced in high food concentrations, although this factor was small and did not explain the slight decrease in CR. They argued that the discrepancy was due to clogging of filters by the algae. Selander \& Tiselius (2003) showed that changes in tail beat frequency had some influence on CR with increasing food concentration, but the greatest effect in their model was unexplained residual error. They were, therefore, unable to rule out the clogging hypothesis.

If filter clogging was solely responsible for masking an equivalent NLAE between the standard and limited food regimes, rather than the result obtained in Table 9, this would imply that the number of particles trapped in the filters would account for approximately $50 \%$ of the standard food regime. With a house renewal rate of $0.25 \mathrm{~h}^{-1}$ at $15^{\circ} \mathrm{C}$ (C. Troedsson, J.L. Acuña, R. Skinees \& E.M. Thompson unpubl. data), a discarded house 
would then trap almost 20000 algal cells. Examination of discarded houses indicates that this figure would be a significant overestimation. Although increased clogging of filters can be an important factor in partly explaining the apparent difference in NLAE, plastic response in the differential regulation of filter structures may also play a role (C. Troedsson, J.L. Acuña, R. Skinnes \& E.M. Thompson unpubl. data). Feeding experiments on the fresh water filter feeding zooplankton Daphnia sp. showed discrepancies in the total energy budget between long-term and short-term experiments (Lampert 1977, Gliwicz 1990), where assimilation in short-term experiments was considerably higher. This was solved upon the discovery that Daphnia sp. responded to varying food concentrations by modifying their filtering screens (Lampert 1994). The difference in the NLAE between Oikopleura dioica given a standard versus a limited food regime might also be explained in a similar manner, through modification of filter structure to varying food concentrations available.

In conclusion, we have demonstrated that the fatty acid composition of Oikopleura dioica reflects dietary composition, in agreement with data on other zooplanktonic filter feeders. This suggests that the nutritional quality of primary production would be transferred to predators of $O$. dioica, and could have effects on their early ontogenetic stages (Støttrup \& Attramadal 1992, Koven et al. 1993, Kraul et al. 1993, Lochmann \& Gatlin 1993, Watanabe 1993, Whyte et al. 1994). It is also intriguing that some key fatty acids in endocrine signaling pathways are up-regulated as gametogenesis commences. There is a strong transition in allocation of resources to reproductive output versus somatic growth in $O$. dioica. Arrest of endocycling in the oikoplastic epithelium responsible for house production is concomitant with acceleration in growth of oocytes (Ganot \& Thompson 2002). Exerting stress on animals prior to this point results in autophagy of the epithelium with a premature acceleration in oocyte differentiation (P. Ganot \& E.M. Thompson unpubl. data). This suggests operation of a rapid inductive signal, switching between epithelial growth and house production on one hand, and oocyte maturation on the other. It will be of interest to determine whether some of the potential endocrine signaling pathways suggested by shifts in fatty acid profiles in this study play roles in such rapid switches in $O$. dioica.

Acknowledgements. We thank A. K. Halvorsen and O. Mjaavatten, University of Bergen, for helpful discussions and technical support, and J.-M. Bouquet and H. Otterå, SARS center, Bergen, for running the appendicularian culture. We also thank anonymous reviewers for constructive criticism that substantially improved the manuscript. This work was supported by grant 145326/432 from the Norwegian Research Council (EMT).

\section{LITERATURE CITED}

Acuña JL, Kiefer M (2000) Functional response of the appendicularian Oikopleura dioica. Limnol Oceanogr 45: 608-618

Bochdansky AB, Deibel D (1999) Functional feeding response and behavioral ecology of Oikopleura vanhoffeni (Appendicularia, Tunicata). J Exp Mar Biol Ecol 233:181-211

Braden LM, Carroll KK (1986) Dietary polyunsaturated fat in relation to mammary carcinogenesis in rat. Lipids 21: 285-288

Broms F, Tiselius P (2003) Effects of temperature and body size on the clearance rate of Oikopleura dioica. J Plankton Res 25:573-577

Cima F, Brena C, Burighel P (2002) Multifarious activities of gut epithelium in an appendicularian (Oikopleura dioica: Tunicata). Mar Biol 141:479-490

Deibel D (1998) Feeding and metabolism of Appendicularia. In: Bone Q (ed) The biology of pelagic tunicates. Oxford University Press, New York, p 139-149

Deibel D, Cavaletto JF, Riehl M, Gardner WS (1992) Lipid and lipid class content of the pelagic tunicate Oikopleura vanhoffeni. Mar Ecol Prog Ser 88:297-302

Dunstan GA, Bailie HJ, Barett SM, Volkman JK (1996) Effect of diet on the lipid composition of wild and cultured abalone. Aquaculture 140:115-127

Falk-Petersen S, Sargent JR, Henderson J, Hegeseth EN, Hop H, Okolodov YB (1998) Lipids and fatty acids in ice algae and phytoplankton from the marginal ice zone in Barents Sea. Polar Biol 20:41-47

Fenaux R, Bone Q, Deibel D (1998) Appendicularian distribution and zoogeography. In: Bone Q (ed) The biology of pelagic tunicates. Oxford University Press, New York, p 151-159

Fernández D, López-Urrutia Á, Fernández A, Acuña JL, Harris R (2004) Retention efficiency of 0.2 to $6 \mu \mathrm{m}$ particles by the appendicularians Oikopleura dioica and Fritillaria borealis. Mar Ecol Prog Ser 266:89-101

Flood PR, Deibel D, Morris CC (1992) Filtration of colloidal melanin from sea-water by planktonic tunicates. Nature 355:630-632

Gadomski DM, Boelert GV (1984) Feeding biology of pelagic larvae of English sole Parophys vetulus and butter sole Isopsetta isolepsis off the Oregon coast. Mar Ecol Prog Ser 20:1-12

Ganot P, Thompson EM (2002) Patterning through differential endoreduplication in epithelial organogenesis of the chordate, Oikopleura dioica. Dev Biol 252:59-71

Gliwicz ZM (1990) Food threshold and body size in cladocerans. Nature 343:638-640

Gorsky G (1980) Optimisation des cultures d'Appendiculaires. Approche du metabolisme de O. dioica. $\mathrm{PhD}$ thesis, University of Paris VI

Graeve M, Kattner G, Hagen W (1994) Diet-induced changes in the fatty acid composition of arctic herbivorous copepods - experimental evidence of trophic markers. J Exp Mar Biol Ecol 182:97-110

Graeve M, Kattner G, Piepenburg D (1997) Lipids in Arctic benthos: Does the fatty acid and alcohol composition reflect feeding and trophic interactions? Polar Biol 18: $53-61$

Grahl-Nielsen O, Andersen M, Derocher AE, Lydersen C, Wiig O, Kovacs KM (2003) Fatty acid composition of the adipose tissue of polar bears and of their prey: ringed seals, bearded seals and harp seals. Mar Ecol Prog Ser 265:275-282

Gunstone FD, Herslof BG (2000) Lipid glossary 2. PJ Barnes \& 
Associates and The Oily Press, Bridgewater

Harwood JL (1994) Lipid metabolism. In: Gunstone FD, Harwood JL, Padley FB (eds) The lipid handbook. Chapman \& Hall, Cambridge, p 605-664

Hasegawa A, Takatsu T, Imura K, Nanjo N, Takahashi T (2003) Feeding habits of Japanese flounder Paralichthys olivaceus larvae in Mutsu Bay, Northern Japan. Nippon Suisan Gakkaishi 69:940-947

Holland DL (1978) Lipid reserves and energy metabolism in the larvae of benthic marine invertebrates. In: Malins DC, Sargent JR (eds) Biochemical and biophysical perspectives in marine biology. Academic Press, New York, p 85-123

Kanazawa A (1985) Essential fatty acid and lipid requirements of fish. In: Cowey CB, Mackie AM, Bell JG (eds) Nutrition and feeding in fish. Academic Press, London, p 281-289

King KR (1982) The population biology of the larvacean Oikopleura dioica in enclosed water columns. In: Grice GD (ed) Biological and chemical research in experimental ecosystems. Springer, New York, p 341-351

Koven WM, Tandler A, Sklan, D, Kissil GW (1993) The association of eicosapentaenoic and docosahexaenoic acids in the main phospholipids of different-age Sparus aurata larvae with growth. Aquaculture 116:71-82

Kraul S, Brittain K, Cantrell R, Nagao T (1993) Nutritional factors affecting stress resistance in the larval mahimahi Coryphaena hippurus. J World Aquat Soc 24:186-193

Kvalheim OM, Karstang TV (1987) A general-purpose program for multivariate data-analysis. Chemometr Intell Lab 2:235-237

Lampert W (1977) Studies of the carbon balance of Daphnia pulex De Geer as related to environmental conditions. 4. Determination of the 'threshold' concentration as a factor controlling the abundance of zooplankton species. Arch Hydrobiol Suppl 48:361-368

Lampert W (1994) Phenotypic plasticity of the filter screens in Daphnia: adaption to a low-food environment. Limnol Oceanogr 39:997-1006

Lochmann RT, Gatlin DM (1993) Evaluation of different types and levels of triglycerides, singly and in combination with different levels of $n-3$ highly unsaturated fatty acid ethyl esters in diets of juvenile red drum, Sciaenops ocellatus. Aquaculture 114:113-130

López-Urrutia Á, Acuña JL (1999) Gut throughput dynamics in the appendicularian Oikopleura dioica. Mar Ecol Prog Ser 191:195-205

López-Urrutia Á, Irigoien X, Acuña JL, Harris R (2003) In situ feeding physiology and grazing impact of the appendicularian community in temperate waters. Mar Ecol Prog Ser 252:125-141

Mousseau L, Fortier L, Legendre L (1998) Annual production of fish larvae and their prey in relation to size-fractionated primary production (Scotian Shelf, NW Atlantic). J Mar Sci $55: 44-57$

Napolitano GE, Ackman RG, Ratnayake WMN (1990) Fatty acid composition in three cultured algal species (Isochrysis galbana, Chaetoceros gracialis and Chaetoceros calcitrans) used as food for bivalve larvae. J World Aquat Soc 21:122-130

Paffenhöfer GA (1975) On the biology of Appendicularia of the southeastern North Sea. Mar Biol 2:437-455

Scott CL, Falk-Petersen S, Sargent JR, Hop H, Lonne OJ, Poltermann M (1999) Lipids and trophic interactions of ice fauna and pelagic zooplankton in the marginal ice zone of the Barents Sea. Polar Biol 21:65-70

Editorial responsibility: Howard Browman

(Associate Editor-in-Chief), Storebø, Norway
Selander E, Tiselius P (2003) Effects of food concentration on the behaviour of Oikopleura dioica. Mar Biol 142:263-270

Shelbourne JE (1962) A predator-prey size relationship for plaice larvae feeding on Oikopleura. J Mar Biol Assoc UK 42:243-252

Spada F, Steen H, Troedsson C, Kallesoe T, Spriet E, Mann M, Thompson EM (2001) Molecular patterning of the oikoplastic epithelium of the larvacean tunicate Oikopleura dioica. J Biol Chem 276:20624-20632

Støttrup JG, Attramadal Y (1992) The influence of different rotifer and artemia enrichment diets on growth, survival and pigmentation in turbot (Scophthalmus maximus L.) larvae. J World Aquat Soc 23:307-316

Thompson EM, Kallesøe, T, Spada F (2001) Diverse genes expressed in distinct regions of the trunk epithelium define a monolayer cellular template for construction of the oikopleurid house. Dev Biol 238:260-273

Ticina V, Vidjak O, Kacic I (2000) Feeding of adult sprat, Sprattus sprattus, during spawning season in the Adriatic Sea. Ital J Zool 67:307-311

Tomita M, Shiga N, Ikeda T (2003) Seasonal occurrence and vertical distribution of appendicularians in Toyama Bay, southern Japan Sea. J Plankton Res 25:579-589

Troedsson C, Bouquet JM, Aksnes DL, Thompson EM (2002) Resource allocation between somatic growth and reproductive output in the pelagic chordate Oikopleura dioica allows opportunistic response to nutritional variation. Mar Ecol Prog Ser 243:83-91

Ulberth F, Henninger M (1995) Determination of the fatty acid profile in fish by a one-step extraction/methylation method. Fat Sci Technol 97:77-80

Uye S, Ichino S (1995) Seasonal variations in abundance, size composition, biomass and production rate of Oikopleura dioica (Fol) (Tunicata: Appendicularia) in a temperate eutrophic inlet. J Exp Mar Biol Ecol 189:1-11

Uye S, Shimazu T, Yamamuro M, Ishitobi Y, Kamiya H (2000) Geographical and seasonal variations in mesozooplankton abundance and biomass in relation to environmental parameters in Lake Shinji-Ohashi River-Lake Nakaumi brackish-water system, Japan. J Mar Syst 26:193-207

Valenzuela A, von Bernhardi R, Valenzuela V, Ramirez G, Alarcon R, Sanhueza J, Nieto S (2004) Supplementation of female rats with $\{\mathrm{FC} 12\} \alpha-$ linolenic acid or docosahexaenoic acid leads to the same omega-6/omega-3 LCPUFA accretion in mother tissues and in fetal and newborn brains. Ann Nutr Metab 48:28-35

Vargas CA, Tönnesson K, Sell A, Maar M and 8 others (2002) Importance of copepods versus appendicularians in vertical carbon fluxes in a Swedish fjord. Mar Ecol Prog Ser 241:125-138

Watanabe H, Kawaguchi K, Hayashi A (2002) Feeding habits of juvenile surface-migratory myctophid fishes (family Myctophidae) in the Kuroshio region of the western North Pacific. Mar Ecol Prog Ser 236:263-272

Watanabe T (1993) Importance of docosahexaenoic acid in marine larval fish. J World Aquat Soc 24:152-161

Webb KL, Chu FLE (1983) Phytoplankton as a food source for bivalve larvae. In: Pruder GD, Langdon CJ, Conklin DE (eds) Biochemical and physiological approaches to shellfish nutrition. Proceedings of the 2nd International Conference on Aquaculture Nutrition, Louisiana State University, Baton Rouge, p 272-291

Whyte JNC (1994) Fatty acid profiles from direct methanolysis of lipids in tissues of cultures species. Aquaculture 75:193-203

Submitted: June 10, 2004; Accepted: October 21, 2004

Proofs received from author(s): March 9, 2005 